\title{
Sensitivity of tropical cyclone characteristics to the radial distribution of sea surface temperature
}

\author{
DeEPika Rai, S PATtNAiK* and P V RAJesh \\ School of Earth Ocean and Climate Science, Indian Institute of Technology, Bhubaneswar, Odisha 751 007, India. \\ ${ }^{*}$ Corresponding author.e-mail: spt@iitbbs.ac.in
}

Sea Surface Temperature (SST) is crucial for the development and maintenance of a tropical cyclone (TC) particularly below the storm core region. However, storm data below the core region is the most difficult to obtain, hence it is not clear yet that how sensitive the radial distribution of the SST impact the storm characteristic features such as its inner-core structures, translational speed, track, rainfall and intensity particularly over the Bay of Bengal. To explore the effects of radial SST distribution on the TC characteristics, a series of numerical experiments were carried out by modifying the SST at different radial extents using two-way interactive, triply-nested, nonhydrostatic Advanced Weather Research and Forecast (WRF-ARW) model. It is found that not only the SST under the eyewall (core region) contribute significantly to modulate storm track, translational speed and intensity, but also those outside the eyewall region (i.e., 2-2.5 times the radius of maximum wind (RMW)) play a vital role in defining the storm's characteristics and structure. Out of all the simulated experiments, storm where the positive radial change of SST inducted within the $75 \mathrm{~km}$ of the storm core (i.e., P75) produced the strongest storm. In addition, N300 (negative radial changes at $300 \mathrm{~km}$ ) produced the weakest storm. Further, it is found that SST, stronger within 2-2.5 times of the RMW for P75 experiment, plays a dominant role in maintaining $10 \mathrm{~m}$ wind speed $\left(\mathrm{WS}_{10}\right)$, surface entropy flux (SEF) and upward vertical velocity $(w)$ within the eyewall with warmer air temperature $(\mathrm{T})$ and equivalent potential temperature $\left(\theta_{\mathrm{e}}\right)$ within the storm's eye compared to other experiments.

\section{Introduction}

The Indian subcontinent frequently suffers by severe weather events that cause a lot of damage to life, economy, agriculture, and socio-economic conditions of the people. Tropical cyclone (TC) is one of the most dangerous severe weather events. TCs develop during the pre- and post-monsoon seasons over the North Indian Ocean (NIO) basins, i.e., Arabian Sea and Bay of Bengal (BoB). Hence, accurate forecast of TC track, intensity, rate of change of intensity, and associated rainfall becomes important. The TC track forecast has improved due to advancement in numerical modelling and data assimilation, but intensity forecast is still a challenging problem (Bender and Ginis 2000; Krishnamurti et al. 2005; Rogers et al. 2006; Rappaport et al. 2009). Inadequate understanding of the physical processes during intensity change (Davis and Bosart 2002; Wang and Wu 2004) and improper physical parameterization in numerical models (Karyampudi et al. 1998; Houze et al. 2006) make the TC intensity forecast more complex. This complexity further enhances during rapid intensification phase of the storm.

TCs extract energy from the underlying warm ocean to intensify and to support its strength. Hence energy exchange at the air-sea interface plays a crucial role in TC intensity change (Malkus

Keywords. Tropical cyclone; sea surface temperature; Phailin. 
and Riehl 1960; Black and Holland 1995). Kaplan and DeMaria (2003) showed that ocean inner-core processes and environmental interaction together, play an important role in modulating TC intensity. The change in TC intensity is very much affected by the multi-scale nonlinear interactions of different phenomena and variables, e.g., sea surface temperature (SST), ocean heat content, vertical wind shear, environmental moisture, innercore dynamics and thermodynamics, cloud microphysics, and air-sea interaction processes (Marks et al. 1998; Wang and $\mathrm{Wu}$ 2004; Pattnaik and Krishnamurti 2007; Pattnaik et al. 2010). A reasonable prediction of the inner-core structural change and storm size may improve the forecast of TC intensity, intensity change, and its rapid intensification (Rappaport et al. 2009; Chen et al. 2011). Warm SST, high relative humidity, and low vertical wind shear are the most favourable environmental factors for the rapid intensification of TCs (Kaplan and DeMaria 2003; Chen et al. 2011). It is also found that the rapid intensification of a TC is strongly affected by the wind-induced surface heat exchange, i.e., WISHE (Emanuel 1986; Rotunno and Emanuel 1987). WISHE describes a positive feedback between the wind speed $10 \mathrm{~m}$ above the surface $\left(\mathrm{WS}_{10}\right)$ and the increase in the surface entropy flux (SEF; sum of sensible and latent heat flux).

It has long been accepted that SST is a dominant factor that affects the maximum possible intensity attainable by a storm (Palmen 1948; Emanuel 1987, 1988) and strongly influences the development and intensification of a TC (Shapiro and Goldenberg 1998; Cione and Uhlhorn 2003; Trenberth and Shea 2006). A number of modelling and observational studies have established the relationship between the change in SST and TC intensity (Miller 1958; Ooyama 1969; Demaria and Kaplan 1994; Bosart et al. 2000; Shay et al. 2000; Cione and Uhlhorn 2003). Previous studies indicate an increasing trend in the more destructive TCs (Emanuel 2005). A study on Odisha super cyclone (1999), using the community mesoscale model (fifth generation) MM5 developed at Pennsylvania State University, showed the impact of SST field and its resolution on the storm intensity and track (Mandal et al. 2007). The storm intensity is enhanced with a higher resolution SST. Yun et al. (2012) used WRF model version 3.2 for simulation of typhoon Maemi (2003) and found that the movement of a TC, induced by different SST, is larger in east-west direction than in the north-south direction.

Previous studies have demonstrated the importance of the energy production outside the eyewall to the TC maximum intensity as well as the TC structure and size (Miyamoto and Takemi 2010; Wang and Xu 2010; Xu and Wang 2010a). Xu and Wang (2010a) artificially modulated the SEF at different radial extents and found that SEF in the eye region (under the eyewall and about 2-2.5 times the radius of maximum wind (RMW) outside the eyewall) of TC contribute little (greatly) to the storm intensity. Studies have shown that SEF outwards, i.e., beyond 2-2.5 times RMW, becomes crucial to the growth of the storm's inner-core size and reduces the storm intensity ( $\mathrm{Xu}$ and Wang 2010a).

Although, it is clear from the above-mentioned discussions that SEF plays a crucial role in the development and maintenance of the TCs, it (SEF) mainly depends on the surface wind speed, the difference between the SST and air temperature $2 \mathrm{~m}$ above the surface, and the difference between the saturation specific humidity at the surface and $2 \mathrm{~m}$ above the surface. With regard to the radial extent of the SEF effect on TC intensity and size, Miyamoto and Takemi (2010) proposed that important radial extent of the TC is about $7-8$ times the RMW, whereas, other studies (Wang and $\mathrm{Xu}$ 2010; $\mathrm{Xu}$ and Wang 2010a) suggested 2-2.5 times the RMW.

Studies demonstrating the radial extent of SEF and SST affecting the storm intensity and structure are mostly based on the western Pacific basin (Wang and Xu 2010; Xu and Wang 2010a; Sun et al. 2013). To the best of our knowledge, similar studies were not carried out over the NIO basins. Hence, the above-mentioned facts prompt a question whether there is any critical radius within which the fluxes and SST play a crucial role in the determination of TC intensity over NIO. In addition, though the interactions between ocean surface below the storm core play a major role in the storm intensity modulation, it is complex to develop correct understanding of the mechanisms because of the lack of data. Therefore, the aim of the present study is to explore the impact of variable SST magnitudes at different radius on the intensification and maintenance of TCs over the BoB.

The organization of the rest of the paper is as follows. Section 2 briefly describes the modelling system, experimental set-up and data used for the initialization and validation of results. Detailed discussion of the results in terms of storm's track, translational speed, intensity, rainfall and vertical profiles of different variables are in section 3, followed by conclusions in section 4 .

\section{Model description and experimental design}

2.1 An overview of the very severe cyclonic storm (VSCS) Phailin (2013)

Very severe cyclonic storm (VSCS) Phailin originated from a remnant cyclonic circulation from 
the South China Sea. The cyclonic circulation, a low pressure over the Tenasserim coast on 6 October 2013, concentrated into a depression over the north Andaman Sea on 8 October, 2013 near $12.0^{\circ} \mathrm{N}, 96.0^{\circ} \mathrm{E}$. Progressing into a cyclonic storm on 9 October, the system further intensified as a VSCS on 10 October over the east BoB. There was rapid intensification of the system from 10 October morning to 11 October morning leading to a decrease (increase) in minimum sea level pressure (maximum sustained wind speed) from $996 \mathrm{hPa}$ $\left(83 \mathrm{~km} \mathrm{~h}^{-1}\right)$ to $940 \mathrm{hPa}\left(212 \mathrm{~km} \mathrm{~h}^{-1}\right)$. According to India Meteorological Department (IMD), Phailin's landfall point was $19.20^{\circ} \mathrm{N}$ and $84.90^{\circ} \mathrm{E}$ at around 1700 UTC 12 October. Phailin was the most intense cyclone that crossed the Indian coast after the Odisha super cyclone of 29 October, 1999. The maximum sustained wind speed reached $215 \mathrm{~km} \mathrm{~h}^{-1}$ which produced a huge storm surge of 2-2.5 $\mathrm{m}$ above the astronomical tide (IMD 2013). Very heavy to extremely heavy rainfall and strong gale winds during Phailin led to floods, large scale structural damage, 38 deaths, and affected 668,268 hectares of crop area (IMD 2013). The coastal inundation was reported maximum upto $500 \mathrm{~m}$ to $1 \mathrm{~km}$ in the low lying areas of Ganjam district (IMD 2013). Odisha and coastal Andhra Pradesh were the most affected regions due to Phailin.

\subsection{Model and experimental design}

An advanced research version of the Weather Research and Forecasting (WRF-ARW) model, version 3.5.1 (Skamarock et al. 2008) is used to generate a set of sensitivity experiments for VSCS Phailin. The simulations are carried out in a twoway interactive manner with three nested domains having horizontal resolution $27 \mathrm{~km}$ (d01), $9 \mathrm{~km}$

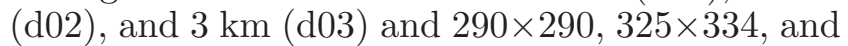
$505 \times 448$ grid points, respectively (figure 1 ). There are 35 levels in vertical direction with the model top set at $50 \mathrm{hPa}$. The model was integrated over 72 hours (0000 UTC, 9 October to 0000 UTC, 12 October 2013) using the time steps $135 \mathrm{~s}, 45 \mathrm{~s}$, and $15 \mathrm{~s}$ for different nests. Between 9 and 12 October, Phailin had intensified from deep depression to VSCS and the system was over the ocean.

The model physics options used include: (a) Hong and Lim (2006) cloud microphysics scheme, WRF Single Moment 6-class (WSM6), which contains water vapour, cloud, ice, rain, snow, and graupel, (b) Yonsei University (YSU) planetary boundary layer (PBL) scheme (Hong et al. 2006), a non-local-K scheme with an explicit entrainment layer and parabolic $\mathrm{K}$ profile in the unstable mixed layer, with MM5 Monin-Obukhov (Zhang and Anthes 1982) surface layer scheme, (c) Dudhia (1989) shortwave and Rapid Radiative Transfer

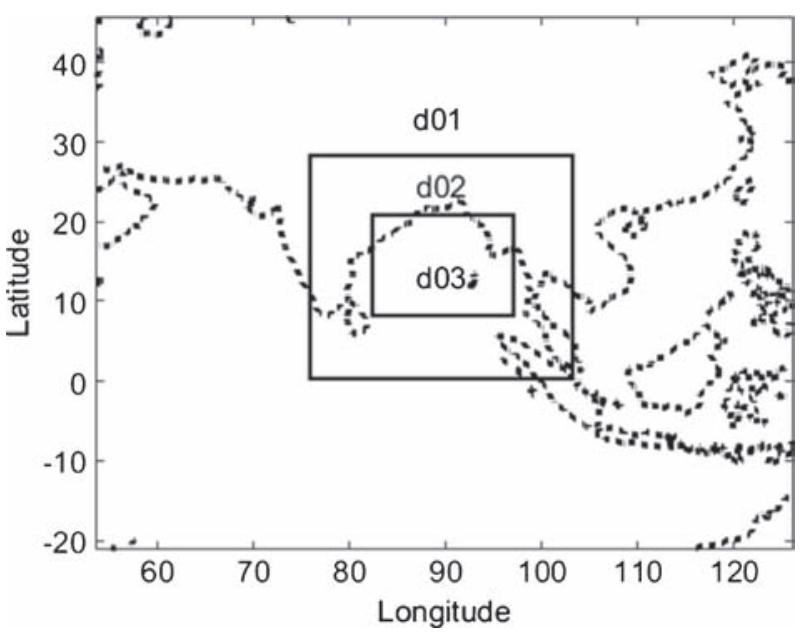

Figure 1. Triple-nested, two-way interactive model domains for the simulation of TC Phailin. The horizontal resolution of d01, d02, and d03 are 27, 9 and $3 \mathrm{~km}$, respectively.

Model (RRTM) for longwave (Mlawer et al. 1997), (d) Unified Noah land-surface model (Ek et al. 2003) for surface flux calculations, and (e) Global/Regional Integrated Model (GRIM) system scheme for shallow cumulus (Hong et al. 2013) for all the three domains. Kain-Fritsch (Kain 2004) is employed for cumulus parameterization for $\mathrm{d} 01$ and d02. Cumulus parameterizations are theoretically valid for the coarser grid and should not be used when the model can resolve the convective eddies itself, i.e., grid spacing $\leq 5 \mathrm{~km}$ (Skamarock et al. 2008), therefore no cumulus parameterization is used for inner most domain (d03). Henceforth, the complete discussions done in this paper are based on the results from d03.

This study is based on a total of eight experiments performed for VSCS Phailin; two control (CNTL1, and CNTL) and six sensitivity experiments (table 1). Here CNTL and CNTL1 are associated with and without SST updates respectively. To assess the sensitivity of TC characteristics to SST changes, six sensitivity experiments are conducted by imposing a change in the SST (i.e., SST anomaly). Here SST anomaly values are $2 \mathrm{~K}(-2 \mathrm{~K})$ within radius $r(75,150$ and $300 \mathrm{~km})$, with linear decrease (increase) in SST anomaly levelling out at $375 \mathrm{~km}$ from radius $r$ (figure 2). This new modified $\mathrm{SST}_{\text {new }}$ (i.e., SST+SST anomaly) is used for SST update in the six sensitivity experiments. Here the six sensitivity experiments are named as P75, P150, P300, N75, N150, and N300, where P and N represent positive and negative anomaly and the numbers define the radius $r$. All the numerical simulations are integrated for $72 \mathrm{hrs}$ with 0000 UTC 9 October, 2013 as the initial condition.

According to the Visakhapatnam radar imageries and IMD reports, the spatial coverage of rainbands (reflectivity $>20 \mathrm{dBZ}$ ) during Phailin were mostly 
Table 1. Summary of control and sensitivity experiments. SST anomaly is the imposed change in RTG_SST_HR.

\begin{tabular}{ll}
\hline Experiment name & \multicolumn{1}{c}{ Modification to the underlying SST (RTG_SST_HR+SST anomaly) } \\
\hline CNTL1 & Without SST update \\
CNTL & With SST update \\
P300 & SST anomaly of $2 \mathrm{~K}$ for $300 \mathrm{~km}$ from storm centre and then linearly decreased to zero for $375 \mathrm{~km}$ \\
P150 & SST anomaly of $2 \mathrm{~K}$ for $150 \mathrm{~km}$ from storm centre and then linearly decreased to zero for $375 \mathrm{~km}$ \\
P75 & SST anomaly of $2 \mathrm{~K}$ for $75 \mathrm{~km}$ from storm centre and then linearly decreased to zero for $375 \mathrm{~km}$ \\
N300 & SST anomaly of $-2 \mathrm{~K}$ for $300 \mathrm{~km}$ from storm centre and then linearly increased to zero for $375 \mathrm{~km}$ \\
N150 & SST anomaly of $-2 \mathrm{~K}$ for $150 \mathrm{~km}$ from storm centre and then linearly increased to zero for $375 \mathrm{~km}$ \\
N75 & SST anomaly of $-2 \mathrm{~K}$ for $75 \mathrm{~km}$ from storm centre and then linearly increased to zero for $375 \mathrm{~km}$ \\
\hline
\end{tabular}

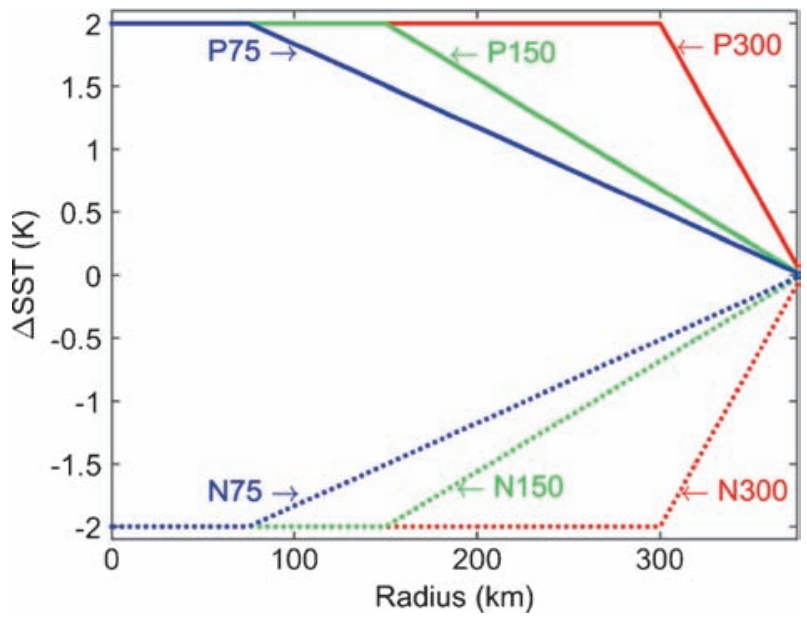

Figure 2. Distribution of SST anomaly for sensitivity experiments P300 (red, solid line), P150 (green, solid line), P75 (blue, solid line), N300 (red, dashed line), N150 (green, dashed line), and N75 (blue, dashed line). Radius represents the distance from the cyclone centre.

within $250-300 \mathrm{~km}$ from the storm centre (IMD 2013). Since the goal of this study is to explore the radius within which the SST becomes important for the intensification and maintenance of TCs, sensitivity experiments are conducted by changing the SST within the area below the storm core, i.e., $375 \mathrm{~km}$ from the storm center.

\subsection{Data used}

National Centres for Environmental Prediction (NCEP) Global Forecast System (GFS) data is used as initial and boundary conditions for all simulations. The temporal and spatial resolution of this data is 3 -hourly and $0.5^{\circ} \times 0.5^{\circ}$, respectively. The lateral boundary conditions for all the simulations are updated at 3-hr interval. NCEP Real-Time Global Sea Surface Temperature High Resolution (RTG_SST_HR) data are used for SST updates in CNTL, and modified SSTs, i.e., RTG_SST_HR+SST anomaly, are used for SST updates in sensitivity experiments. RTG_SST_HR was implemented into operations on 25 September,
2005 with temporal and spatial resolution of $24 \mathrm{hrs}$ and $0.083^{\circ} \times 0.083^{\circ}$, respectively (Gemmill et al. 2007). All the SSTs are updated at 3-hr interval. RTG_SST_HR data use the most recent 24-hr in-situ data (fixed buoys, drifting buoys, ships) and National Oceanic and Atmospheric Administration (NOAA) 17 and 18 Advanced Very High Resolution Radiometer (AVHRR) satellite data. More details about RTG_SST_HR data are given in Gemmill et al. (2007). IMD's 3-hourly track and intensity data, maximum wind speed (MWS) and minimum sea level pressure (MSLP), are used to validate the model track and intensity.

\section{Results and discussions}

This study is based on eight-experiments, i.e., CNTL1, CNTL, P300, P150, P75, N300, N150, and N75 (table 1). A comparison of simulated track and intensity (MSLP and MWS) errors between CNTL and CNTL1 showed an improved forecast skill ( $\geq 15 \%$ ) for CNTL (figure not shown). Based on this result, further discussions in this section are done for CNTL and six sensitivity experiments.

\subsection{Effect of SST changes at different radial extents on TC intensity}

\subsubsection{Track, track error, and translation speed}

To show the impact of SST on storm track, simulated tracks up to 72 hrs (i.e., 0000 UTC 9 October to 0000 UTC 12 October, 2013) from CNTL and six sensitivity experiments along with IMD are shown in figure 3(a). The storm's centre has been identified as the location of MSLP. According to IMD, Phailin's trajectory was northwesterly, but the positive (negative) anomaly of SST under the storm core region (up to a distance of $375 \mathrm{~km}$ ) induces a rightward (leftward) drift in track with respect to IMD (figure 3a). These results are in synchronous with the findings of Tuleya and Kurihara (1982) and Yun et al. (2012) studies over the tropical Atlantic and western Pacific basins. 

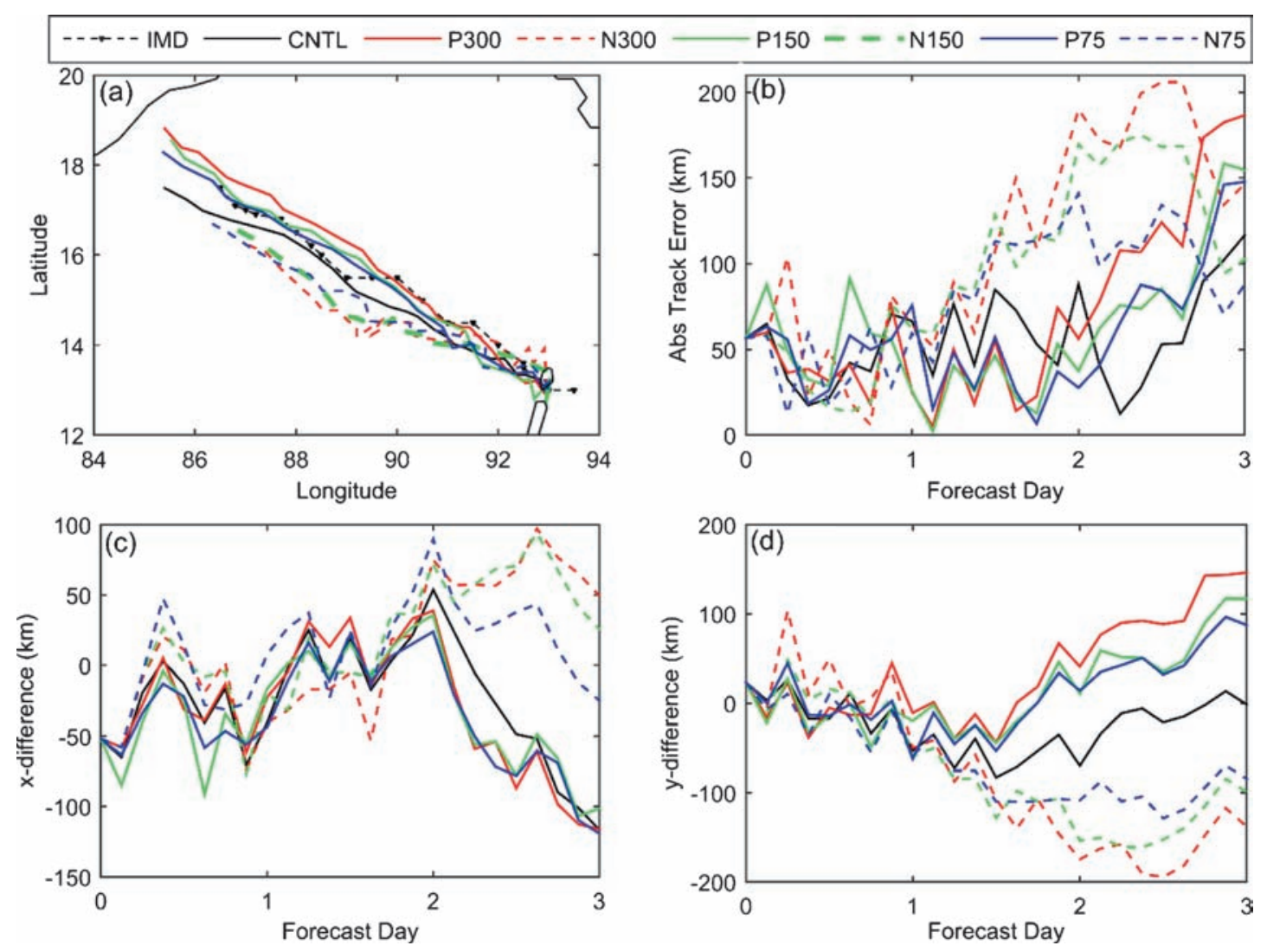

Figure 3. (a) Phailin trajectory, (b) track error, (c) x-difference, sensitivity experiments minus CNTL, and (d) y-difference, sensitivity experiments minus CNTL, based on the numerical simulations from 0000 UTC 9 October 2013 to 0000 UTC 12 October 2013, with respect to observed best-track IMD data. Positive distances in (c) and (d) represent the eastward and northward drift with respect to IMD.

Figure 3(b) shows the track errors with respect to IMD best track for $72 \mathrm{hrs}$ (0000 UTC 9 October to 0000 UTC 12 October, 2013). Initially, during 0 to 36 hrs (i.e., 0000 UTC 9 October to 1200 UTC 10 October), the track errors for all the experiments are $<100 \mathrm{~km}$. From $36 \mathrm{hrs}$ onwards, the track errors for N300, N150 and N75 experiments are $>100 \mathrm{~km}$ (figure 3b). However, track errors for P300, P150, and P75 experiments are $>100 \mathrm{~km}$ after 51, 66 and 66 hours, respectively. Therefore, the track errors $(>100 \mathrm{~km})$ for positive anomaly experiments are delayed by more than $15 \mathrm{hrs}$ compared to negative anomaly experiments.

During 0 to $36 \mathrm{hrs}$, storm's average translation speed (TS) for IMD, CNTL, P300, P150, P75, N300, N150 and N75 are around 3.7, 2.8, 2.9, 3.1, $3.0,3.2,2.8$, and $3.0 \mathrm{~m} \mathrm{~s}^{-1}$, respectively. Hence, all the simulated storms moved relatively slower than the observed (i.e., IMD). From 39 to 72 hrs, storm's average TS for IMD, CNTL, P300, P150, P75, N300, N150 and N75 are around 3.5, 4.6, 5.2, 4.8, $4.9,3.1,3.4$, and $3.9 \mathrm{~m} \mathrm{~s}^{-1}$, respectively. The results indicate that the positive (negative) SST anomaly below the storm core region moderately impact the TS during the initial hours of storm development but significantly impact its TS during the mature phase of the storm.

The storm track exhibits differences in the eastwest, i.e., $\mathrm{x}$-differences (figure $3 \mathrm{c}$ ) as well as northsouth, i.e., y-differences (figure 3d). It is found that a positive (negative) SST anomaly leads to a larger north-westward (south-eastward) drift in the track forecasts. At 66 hrs, the drifts for P300 and N300 are the largest in north-westward and southeastward direction, respectively (figure 3c, d) with respect to IMD track. For P300, results show that there is a westward drift of $98 \mathrm{~km}$ and northward drift of $142 \mathrm{~km}$ and for N300, the eastward drift is $77 \mathrm{~km}$ and southward drift is $148 \mathrm{~km}$. These results suggest that SST anomaly (i.e., positive/negative) under the storm core region significantly impact its track and TS forecast.

\subsubsection{Intensity}

The intensity of a storm is defined in terms of MSLP and MWS. Though all the simulations are started from the same initial intensity, i.e., $1002 \mathrm{hPa}$ (figure 4a), it is found that P75 experiment produced the most intensified storm 

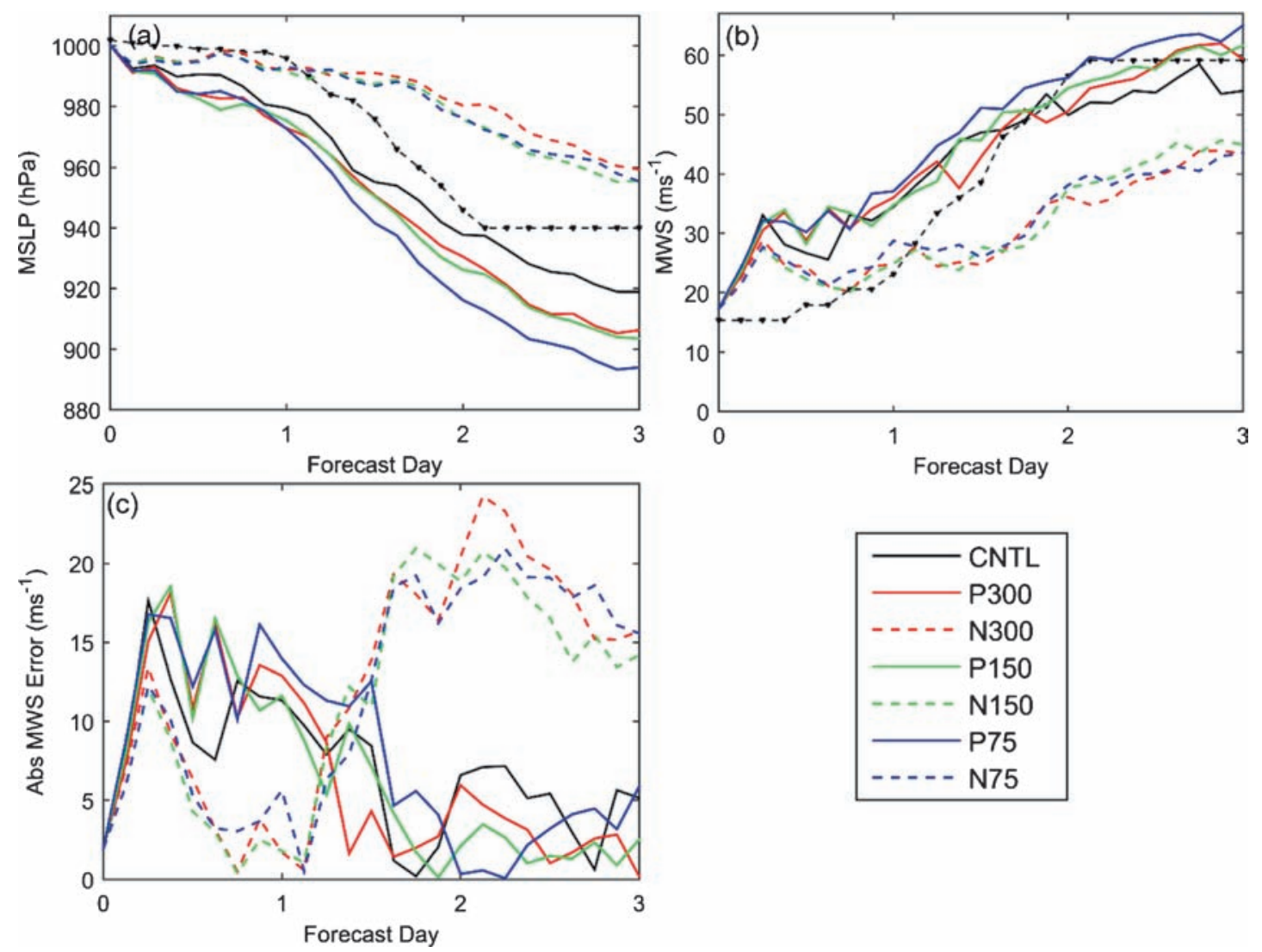

Figure 4. Time series of (a) MSLP and (b) MWS and (c) absolute MWS error for all the experiments, based on the numerical simulations from 0000 UTC 9 October 2013 to 0000 UTC 12 October 2013, and best track data. MWS errors are calculated with respect to observed best-track IMD data.

(i.e., $893 \mathrm{hPa}$ at $69 \mathrm{hrs}$ ) among all the simulations and the observed (IMD) (figure 4a). Negative SST anomaly experiments (i.e., N75, N150, N300) produced weaker storms compared to IMD and positive anomaly experiments. N300 produced the weakest storms with MSLP of $980 \mathrm{hPa}$ at $51 \mathrm{hrs}$, whereas, MSLP for N150 and N75 at 51 hrs are 973 and $972 \mathrm{hPa}$, respectively.

MWS shows a clear distinction between the positive and negative SST anomaly experiments. CNTL, P300, P150, and P75 simulated more intensified storms ( $>10 \mathrm{~m} \mathrm{~s}^{-1}$ ) than N300, N150, and N75 (figure 4b). The MWS errors for CNTL, P300, P150, and P75 showed a decreasing trend (18-5 $\mathrm{m} \mathrm{s}^{-1}$ ) during 06-36 hrs (i.e., 0600 UTC 9 October to 1200 UTC 10 October) but have minimally changed (i.e., $0-7 \mathrm{~m} \mathrm{~s}^{-1}$ ) during $39-72 \mathrm{hrs}$, i.e., 1500 UTC 10 October to 0000 UTC 12 October (figure 4c). The MWS errors for N300, N150, and N75 have increased from 2 to $24 \mathrm{~m} \mathrm{~s}^{-1}$ for N300 during 24-48 hrs (i.e., 0000 UTC 10 October to 0000 UTC 11 October) and decreased up to $15 \mathrm{~m} \mathrm{~s}^{-1}$ from 51 hrs (i.e., 0300 UTC 11 October) onwards (figure 4c).

These results suggest that positive (negative) SST anomaly below the storm core region drastically impact TC intensity. The positive (negative) anomaly experiments show a tendency for an early (delayed) intensification of the storm after $18 \mathrm{hrs}$ (36 hrs) of the simulation. MWS simulated by positive SST anomaly experiments are able to capture the IMD MWS better than CNTL during the mature phase of the storm (i.e., 39-72 hrs). Less areal distance of positive SST anomaly (i.e., P75) have a substantial impact on storm core and strongly amplify the rate of intensification. These results clearly indicate that SST modified in different radial areas, gives the first hint that which part of the storm is most sensitive to SST, inner core of the storm or the larger area beyond the inner core of the storm.

\subsubsection{Rate of intensification}

All the experiments simulate a continuous intensification, almost up to $72 \mathrm{hrs}$ (figure $4 \mathrm{a}, \mathrm{c}$ ), but the intensification rate (i.e., rate of pressure fall) is not same. For CNTL and positive SST anomaly (i.e., P300, P150, and P75), the intensification rate is continuously increasing from 18 to $36 \mathrm{hrs}$ (i.e., 1800 UTC 9 October to 1200 UTC 10 October) and decreasing from 39 to $60 \mathrm{hrs}$, i.e., 1500 UTC 10 October to 1200 UTC 11 October (figure 5a). Unlike positive SST anomaly experiments, negative 

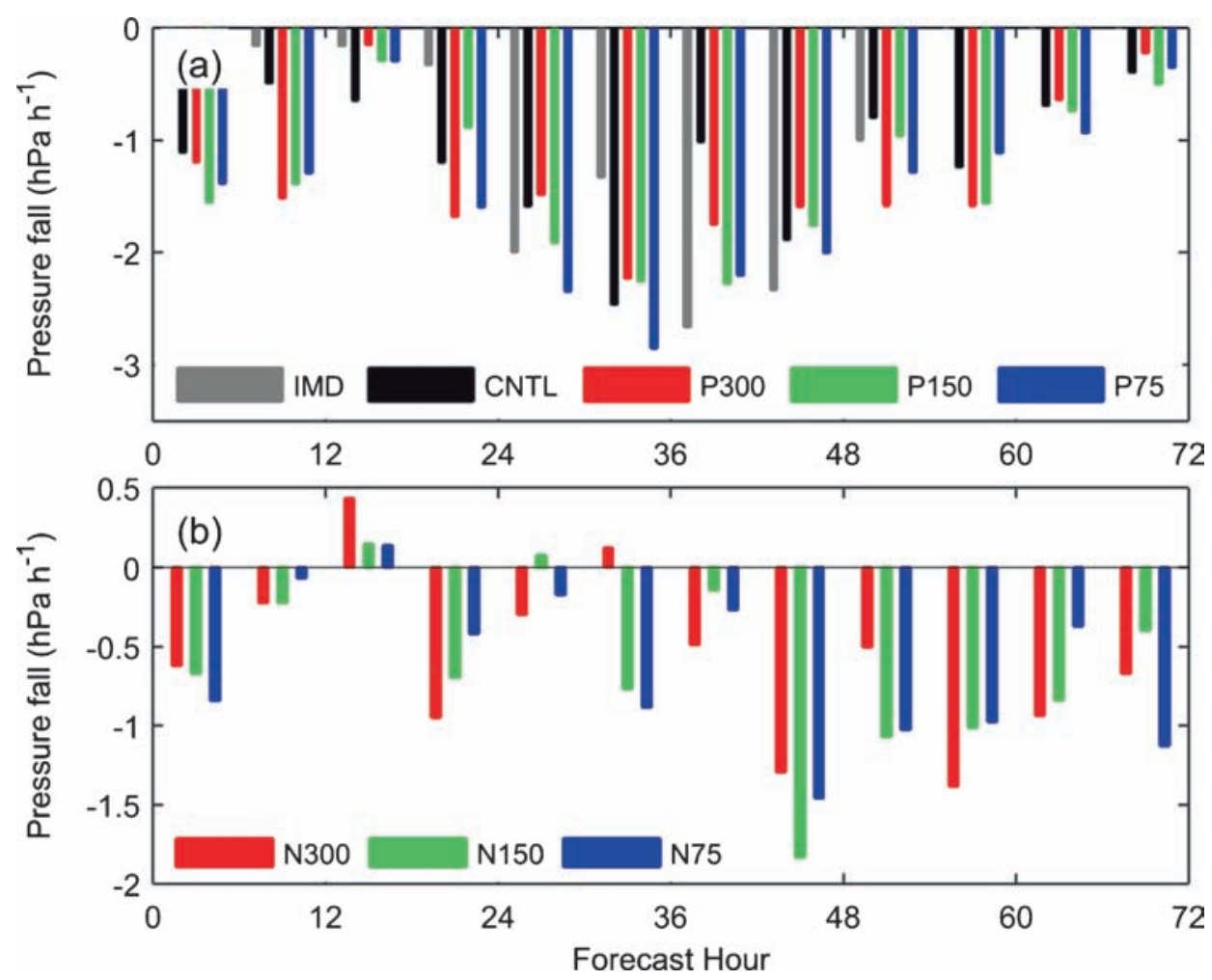

Figure 5. Rate of pressure fall $\left(\mathrm{hPa} \mathrm{h}^{-1}\right)$ for (a) IMD, CNTL and positive SST anomaly experiments and (b) negative SST anomaly experiments, based on the numerical simulations from 0000 UTC 9 October 2013 to 0000 UTC 12 October 2013.

SST anomaly experiments (i.e., N300, N150, and N75) show only a decreasing trend in the rate of intensification (i.e., weaker storms) within 39 to $60 \mathrm{hrs}$ (figure 5b).

On the basis of drop in MSLP, it is found that CNTL, P300, P150, and P75 simulated storms started intensifying rapidly at $18 \mathrm{hrs}$ (i.e., 1800 UTC 9 October 2013), 15 hrs (i.e., 1500 UTC 9 October 2013), $15 \mathrm{hrs}$ and $9 \mathrm{hrs}$ (i.e., $0900 \mathrm{UTC}$ 9 October 2013), respectively. The intensification rate shows an increasing trend (i.e., -0.2 to -3 $\mathrm{hPa}$ ) during 18 to $36 \mathrm{hrs}$ and decreasing trend (i.e., -3 to $-0.5 \mathrm{hPa}$ ) during 39 to $60 \mathrm{hrs}$ for P300, P150, and P75 (figure 5a). N300, N150, and N75 simulated storm does not have any rapid intensification phase, but intensification rate shows a decreasing trend (i.e., -1.5 to $-0.5 \mathrm{hPa}$ ) during 39-60 hrs (figure 5b). From here onwards, the discussions have been divided into three parts focusing on intensification phase,

- CNTL and positive SST anomaly experiments (P300, P150, and P75) from 18 to 36 hrs (SET1),

- CNTL and positive SST anomaly experiments (P300, P150, and P75) from 39 to 60 hrs (SET2),

- CNTL and negative SST anomaly experiments (N300, N150, and N75) from 39 to 60 hrs (SET3).

There is no systematic pattern in the intensification rate for negative SST anomaly experiments
(N300, N150, and N75) from 18 to 36 hrs, hence this period is not considered in this discussion. In this study, TC's rapid intensification is defined in terms of MSLP, i.e., drop in MSLP $\geq 42 \mathrm{hPa}$ over a 24-hr period (Holliday and Thompson 1979). TC's rapid intensification can also defined in terms of MWS, increase in MWS $\geq 15 \mathrm{~m} \mathrm{~s}^{-1}$ over a 24 -hr period (Kaplan and DeMaria 2003).

\subsection{Surface diagnosis}

\subsubsection{Radius of maximum wind}

From the previous discussion, it is established that TC intensity is heavily dependent on the radial extent of SST anomaly under the TC inner core and shows an increasing trend in intensification as the SST anomaly area converges towards the TC centre (figure 4). Between 18 and 60 hrs, P75 (N150) storm has the highest intensification rate among positive (negative) anomaly experiments. The difference of minimum MSLP $\left(\mathrm{MSLP}_{\min }\right)$ and maximum MWS (MWS ${ }_{\max }$ ) between P75 and P300 are $10 \mathrm{hPa}$ and $4 \mathrm{~m} \mathrm{~s}^{-1}$ respectively. Similar difference between N150 and N300 storms are $6 \mathrm{hPa}$ and $3 \mathrm{~m} \mathrm{~s}^{-1}$, respectively (table 2 ).

It is found that the radius of constant SST anomaly for the P75 (N150), is about 2 to 2.5 times of time-averaged RMW 32.7 (62.9) km during the TC intensification period (table 2). The 
time-averaged RMW for all the sensitivity experiments are greater than RMW of CNTL (i.e., $27 \mathrm{~km}$ ). The range of RMW for CNTL, P300, P150, P75, N300, N150, and N75 are 15-39, 29-54, 19-45, 25-51, 12-100, 22-77, and 21-91 km, respectively during the intensification period (i.e., 18-60 hrs). The results suggest that SST below the inner-core and outside the eyewall up to a radius of about 2-2.5 times of RMW contribute greatly to the storm intensification.

\subsubsection{Surface wind speed and surface entropy flux}

SEF plays a crucial role in the development and maintenance of TC (Xu and Wang 2010a) and $10 \mathrm{~m}$ wind speed $\left(\mathrm{WS}_{10}\right)$ affects SEF significantly.

Table 2. Summary of control and sensitivity experiments. $M S L P_{\min }$ and $M W S_{\max }$ are minimum MSLP, maximum MWS within the TC intensification period 1800 UTC 9 October to 1200 UTC 11 October, 2013. RMWave, the radius of maximum wind at $10 \mathrm{~m}$ above the surface, is averaged within TC intensification period 1800 UTC 9 to 1200 UTC 11 October, 2013.

\begin{tabular}{lccc}
\hline $\begin{array}{l}\text { Experiment } \\
\text { name }\end{array}$ & $\begin{array}{c}\text { MSLP } \\
(\mathrm{hPa})\end{array}$ & $\begin{array}{c}\mathrm{MWS}_{\max } \\
\left(\mathrm{m} \mathrm{s}^{-1}\right)\end{array}$ & $\begin{array}{c}\text { RMW } \\
(\mathrm{km})\end{array}$ \\
\hline CNTL & 925.5 & 54.0 & 27 \\
P300 & 911.6 & 58.1 & 39.3 \\
P150 & 911.0 & 58.1 & 30.0 \\
P75 & 901.8 & 62.3 & 32.7 \\
N300 & 969.0 & 39.5 & 79.2 \\
N150 & 963.1 & 42.6 & 62.9 \\
N75 & 964.4 & 40.0 & 70.3 \\
\hline
\end{tabular}

The time-radius cross section of $\mathrm{WS}_{10}$ and SEF for SET1, SET2, and SET3 are presented in figures 6-8. Results show that $\mathrm{WS}_{10}(\mathrm{SEF})$ values for P75 are much larger, about $5 \mathrm{~m} \mathrm{~s}^{-1}$ or more $\left(500 \mathrm{Wm}^{-2}\right.$ or more), near the eyewall region (within $50 \mathrm{~km}$ ) and relatively smaller outside than other experiments (figure 6). Similar characteristics are shown by SET2 (figure 7). The larger magnitude of $\mathrm{WS}_{10}$ and SEF are also found in SET3 for N150 in comparison to N300 and N75. Magnitude of $\mathrm{WS}_{10}$ and SEF for N150 are greater than $\mathrm{N} 300$ and N75 by about $5 \mathrm{~m} \mathrm{~s}^{-1}$ and $500 \mathrm{Wm}^{-2}$ respectively (figure 8c).

As the distribution of $\mathrm{WS}_{10}$ and SEF are very much concentrated in the vicinity of the eyewall for P75 (N150), it helps to sustain the storm by supplying energy to its eyewall, while in other experiments, i.e., CNTL, P300, P150, N300, and N75, $\mathrm{WS}_{10}$ and SEF are decentralized over a relatively larger area and thus contribute little to the TC intensification. It is also found that the temporal gradient in $\mathrm{WS}_{10}$ and SEF are stronger, 0.1$0.9 \mathrm{~m} \mathrm{~s}^{-1} \mathrm{~h}^{-1}$ and $19-21 \mathrm{Wm}^{-2} \mathrm{~h}^{-1}$ respectively, in SET1 (figure 6) than SET2 (figure 7) near the eyewall. It is because SET1 belongs to the time period when the cyclone was in the intensifying stage and was not matured, whereas during SET2 (figure 7) it was a mature storm. Though SET2 and SET3 belong to the same time period, i.e., 39-60 hrs, $\mathrm{WS}_{10}$ (SEF) for SET2 (figure 7) is about $20 \mathrm{~m} \mathrm{~s}^{-1}$ or more (2500 $\mathrm{Wm}^{-2}$ or more) larger than SET3 (figure 8). It is also found that like SET1, SET3 has a stronger temporal gradient in $\mathrm{WS}_{10}$ and $\mathrm{SEF}$, and $\mathrm{WS}_{10}$ and SEF are more centralized towards

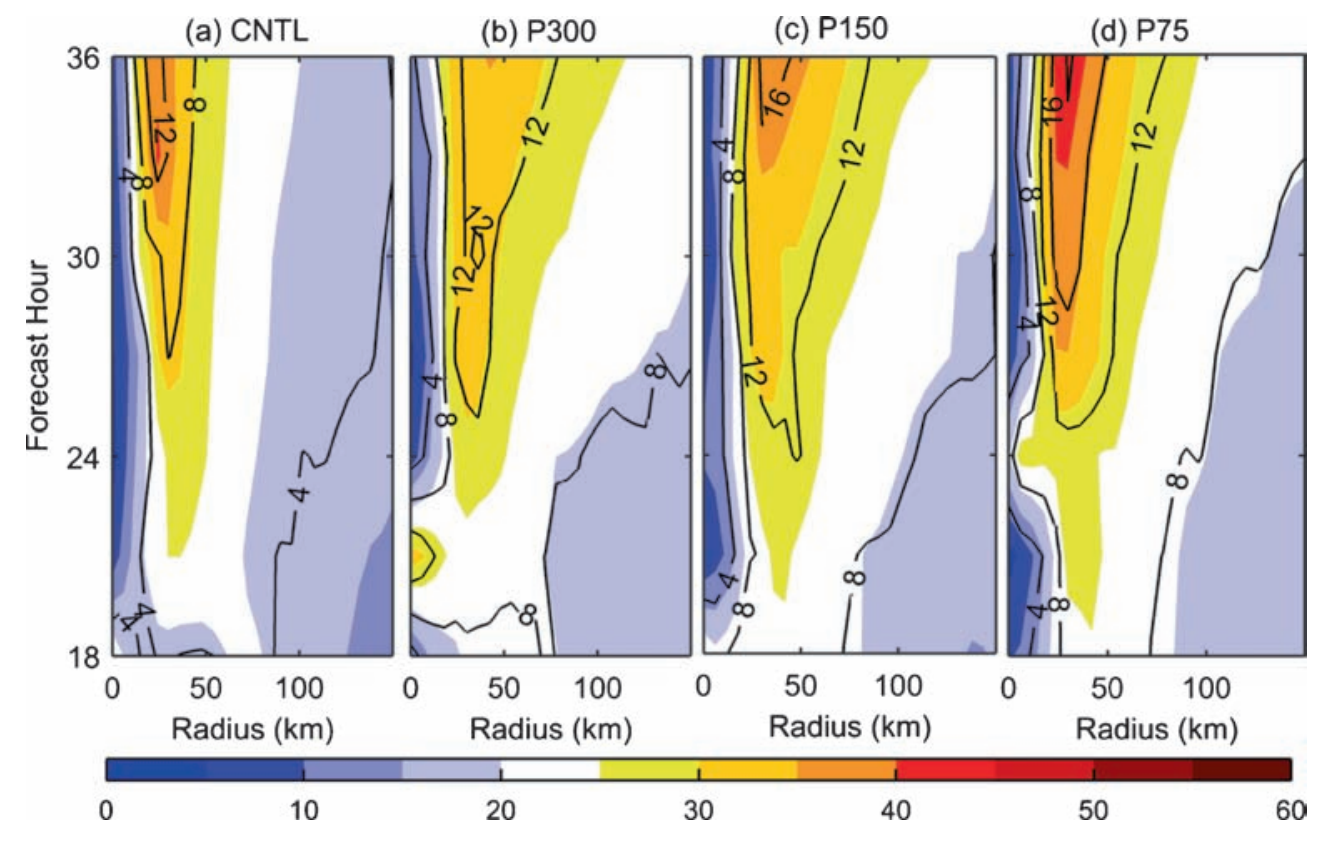

Figure 6. Time-radius plot for $10 \mathrm{~m}$ wind speed, i.e., $\mathrm{WS}_{10}\left(\mathrm{~m} \mathrm{~s}^{-1}\right.$, shaded $)$ and surface entropy flux, i.e., SEF $\left(10^{2} \times\right.$ $\mathrm{Wm}^{-2}$, contours) for SET1 (a) CNTL, (b) P300, (c) P150 and (d) P75. 
(a) CNTL

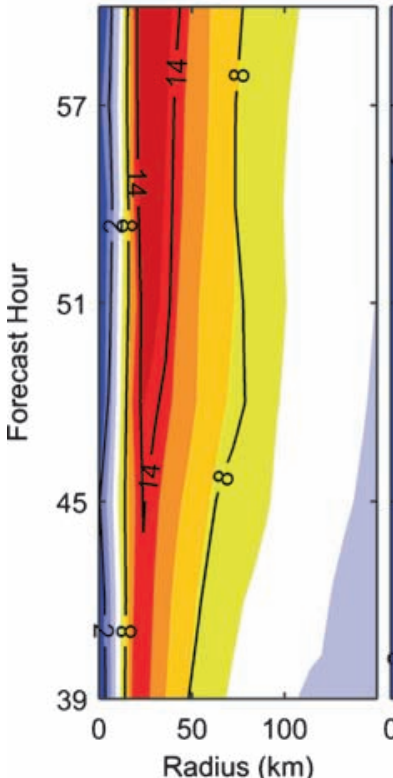

(b) P300

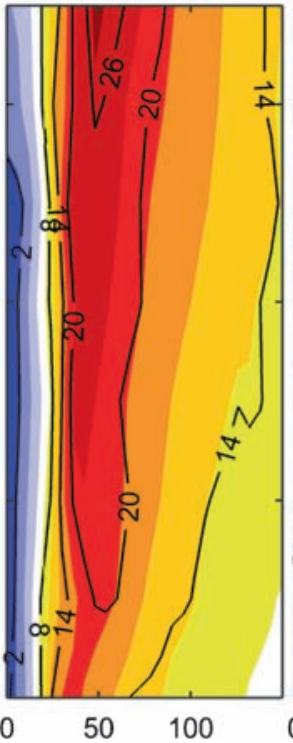

(c) P150

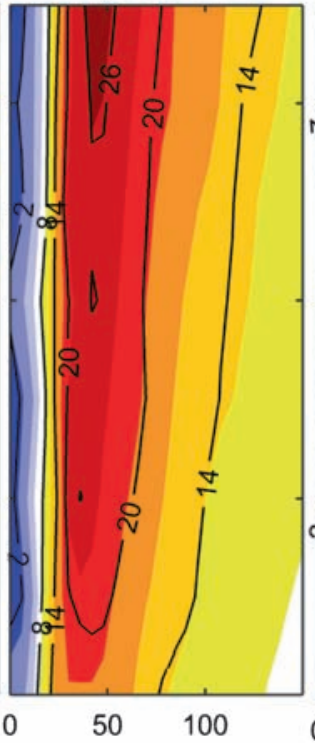

(d) P75

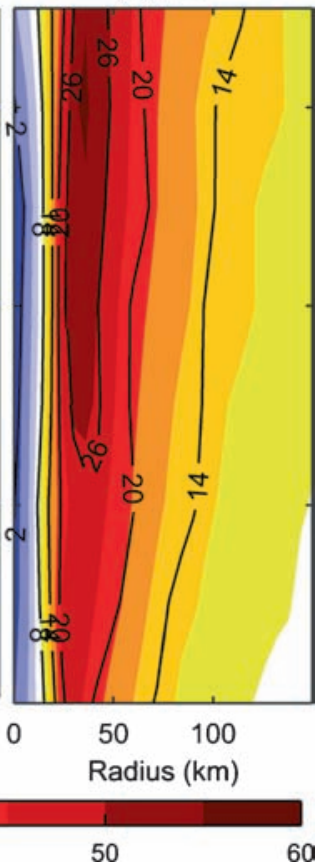

60

Figure 7. Same as figure 6, but for SET2.

(a) CNTL

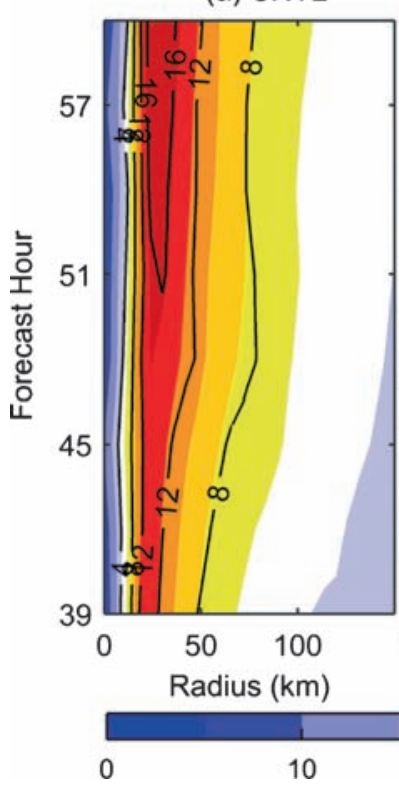

(b) N300

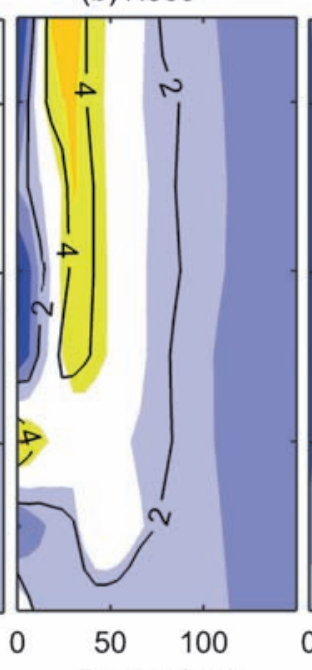

(c) N150

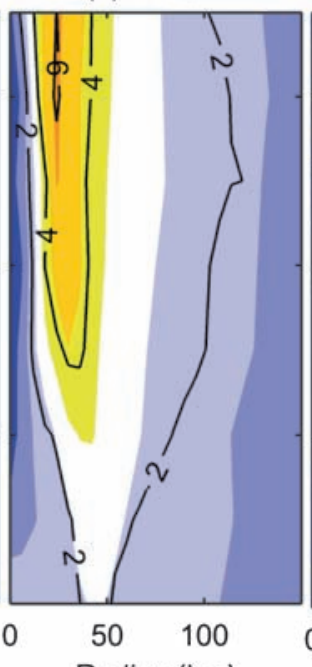

(d) N75

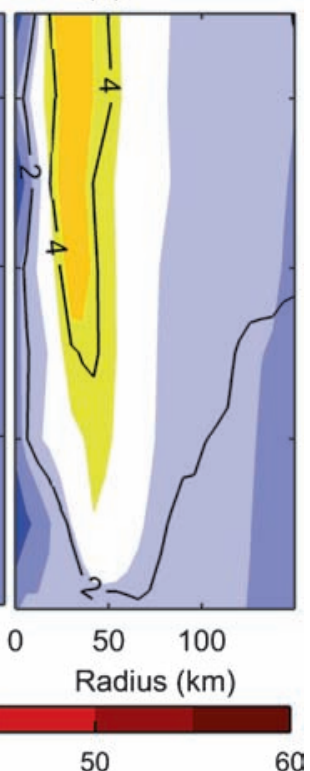

Figure 8. Same as figure 7, but for SET3 (a) CNTL, (b) N300, (c) N150, and (d) N75.

the eyewall for N150 (figure 8). The common feature in these plots is that the magnitude of $\mathrm{WS}_{10}$ and SEF are smaller in the eye compared to the eyewall and outside the eyewall.

\subsubsection{Rain rate}

The rain rates for SET1 (figure 9), SET2 (figure 10), and SET3 (figure 11) are time-averaged during 18 to 36,39 to 60 , and 39 to $60 \mathrm{hrs}$, respectively.
These are the periods which show a robust change in the intensification rate (figure 5). The magnitude of rain rate within the eye of the storm for all the sensitivity experiments are less compared to CNTL (i.e., $>5 \mathrm{~mm} \mathrm{~h}^{-1}$ ) (figures 9-11) and this difference increases from intensifying phase (figure 9) to mature phase (figure 10). For SET1 (figure 9), rain rates are significantly lower (about $15 \mathrm{~mm} \mathrm{~h}^{-1}$ ) than that for SET2 (figure 10) within $150 \mathrm{~km}$ radius from the center. A comparison 


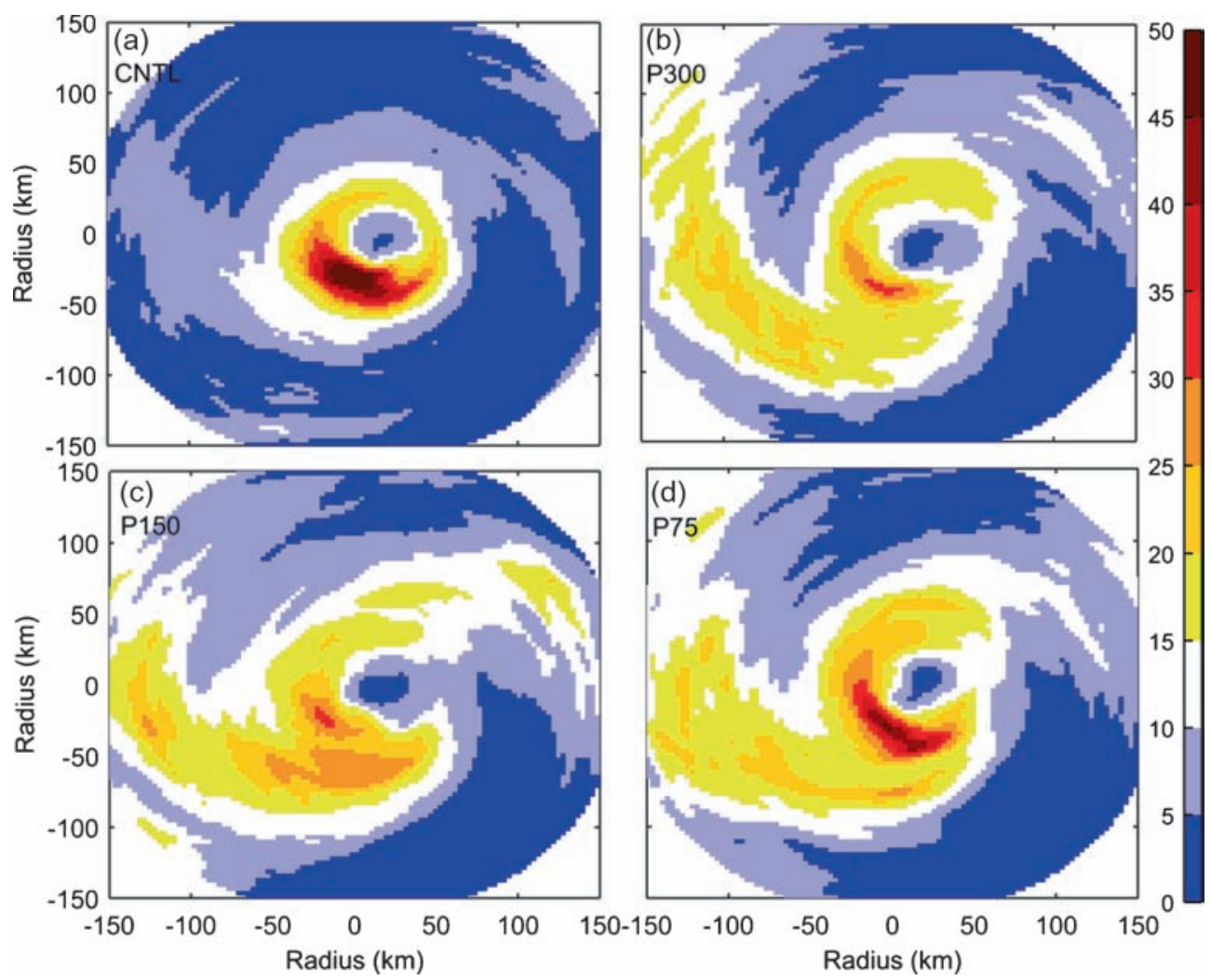

Figure 9. Plane view of the rain rate $\left(\mathrm{mm} \mathrm{h}^{-1}\right)$ for SET1 (a) CNTL, (b) P300, (c) P150, and (d) P75, time-averaged during $18-36 \mathrm{hrs}$.

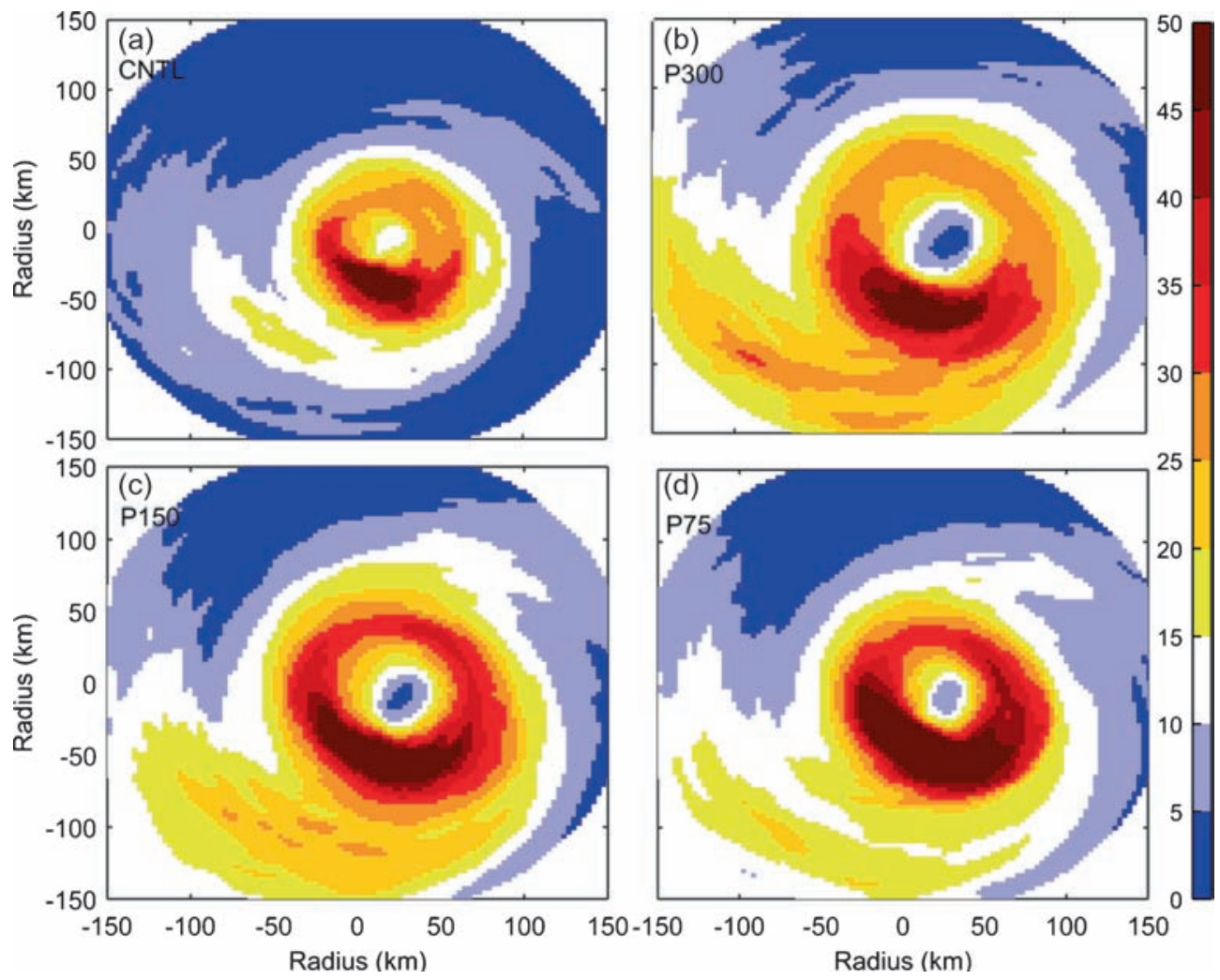

Figure 10. Same as figure 9, but for SET2, i.e., time-averaged during 39-60 hrs. 

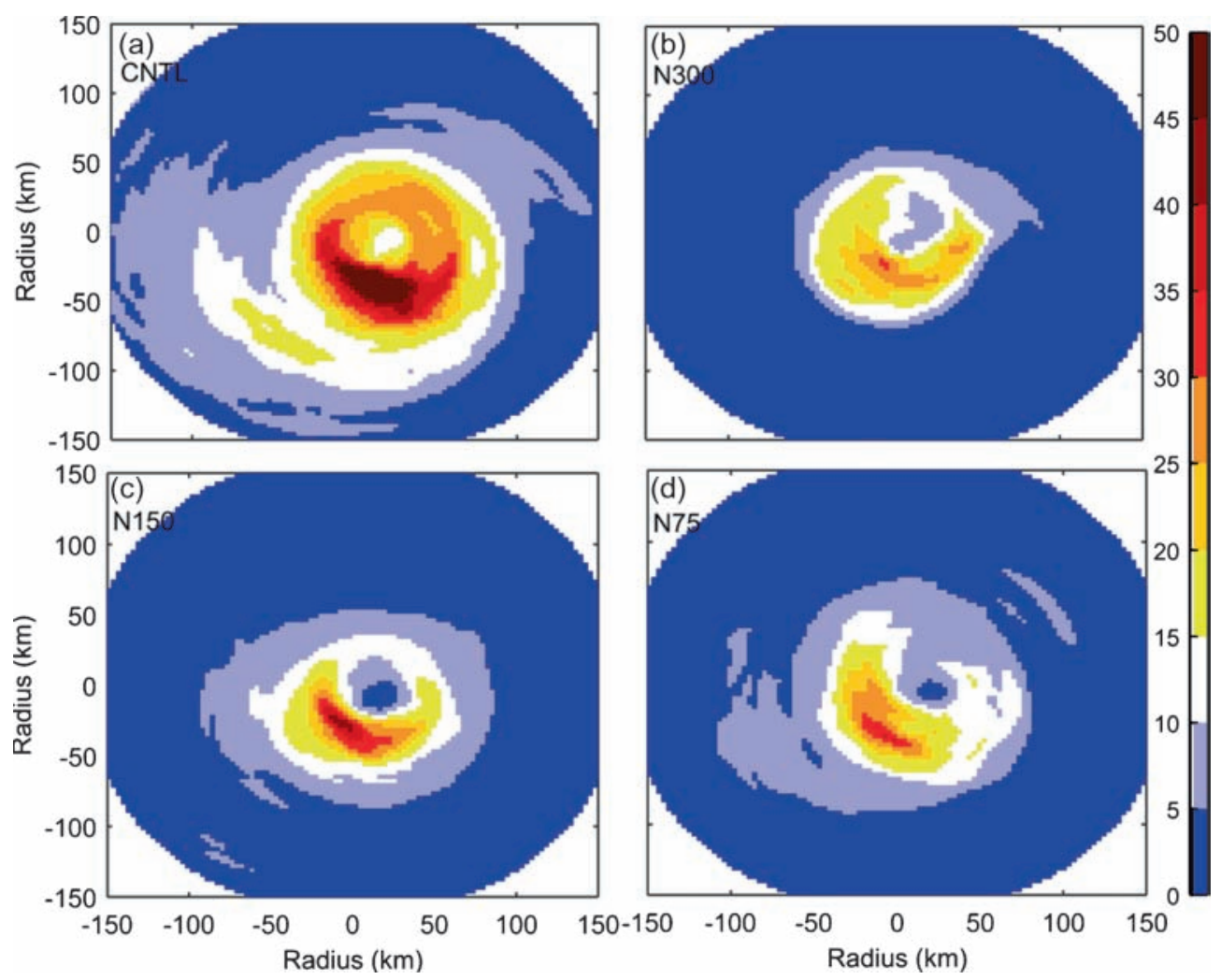

Figure 11. Same as figure 10, but for SET3 (a) CNTL, (b) N300, (c) N150, and (d) N75.

of rain rate coverage area between CNTL and sensitivity experiments (i.e., P300, P150, and P75) show a clearly distinct pattern for SET2 (figure 10). In SET2, the coverage area of rain rate, more than $15 \mathrm{~mm} \mathrm{~h}^{-1}$, for CNTL and P75 are $<75 \mathrm{~km}$, whereas, $75-100 \mathrm{~km}$ for others, i.e., for P300 and P150 (figure 10). Strong winds in the outer region (as found in P300 and P150 in figure 7) lead to stronger SEF in the outer region, which favours more convective activity in the outer rainbands $(>75 \mathrm{~km})$ and reduces the storm intensity ( $\mathrm{Xu}$ and Wang 2010b).

The most intense rain rate $\left(>45 \mathrm{~mm} \mathrm{~h}^{-1}\right)$ is found in P75 storm for SET2. Further, P75 simulates more organized rainbands than P300 and P150 (figures 9-10). Stronger storms such as P75, P150, P300 (SET1 and SET2), produce an intense rain rate than weaker storms, i.e., N75, N150 and N300 (figure 11). However, among negative anomaly experiments, N150 shows the intense rain rate $\left(>30 \mathrm{~mm} \mathrm{~h}^{-1}\right.$ ) compared to the other two. The major chunk of the rainfall is more concentrated in the southwest quadrant of the storm for all the experiments (figures 9-11). This is because, as the simulated storm is moving northwestward (figure 3a), the counterclockwise rotation drags the wind from higher latitude to lower latitude. The movement of winds towards lower latitude reduces the coriolis parameter, which increases the relative vorticity in order to keep the potential vorticity conserved (Holton 2004). This increase in the relative vorticity increases the atmospheric instability and hence convection in the southwest quadrant of the storm facilitates the rainfall. These results suggest that the distribution of SST anomaly in the inner-core region of a TC strongly modifies the amount, intensity and spatial distribution of rainfall of the storm (figures 9-11). It also appears that the decrease in the SST decreases the amount of energy transferred from the surface to the atmosphere and reduces convection, hence decreasing the intensity and amount of rainfall of the storm.

The SST anomaly has a significant influence on the outer spiral rainbands. A comparison of the rain distribution over $300 \mathrm{~km}$ area from the storm center shows that the rainbands in the outer region are stronger $(>5 \mathrm{dBz})$ in P300 and P150 than in P75 (figure 12). It is also found that the wind magnitude is $50 \mathrm{~m} \mathrm{~s}^{-1}$ in $\mathrm{P} 75$, whereas, it is $40 \mathrm{~m} \mathrm{~s}^{-1}$ in other experiments near the eyewall for SET2 (figure 12). Outer spiral rainbands are mainly driven by diabatic heating due to phase change in rainbands. Wang (2009) showed that diabatic heating in the outer rainbands cause pressure fall in the lower troposphere, which reduces the pressure gradient across the eyewall and weaken the tangential wind near the RMW. The weakening tangential wind near the RMW weaken the storm intensity. In the present study, outer spiral rainbands in P75 are weaker $(>5 \mathrm{dBz})$ than P150 and 

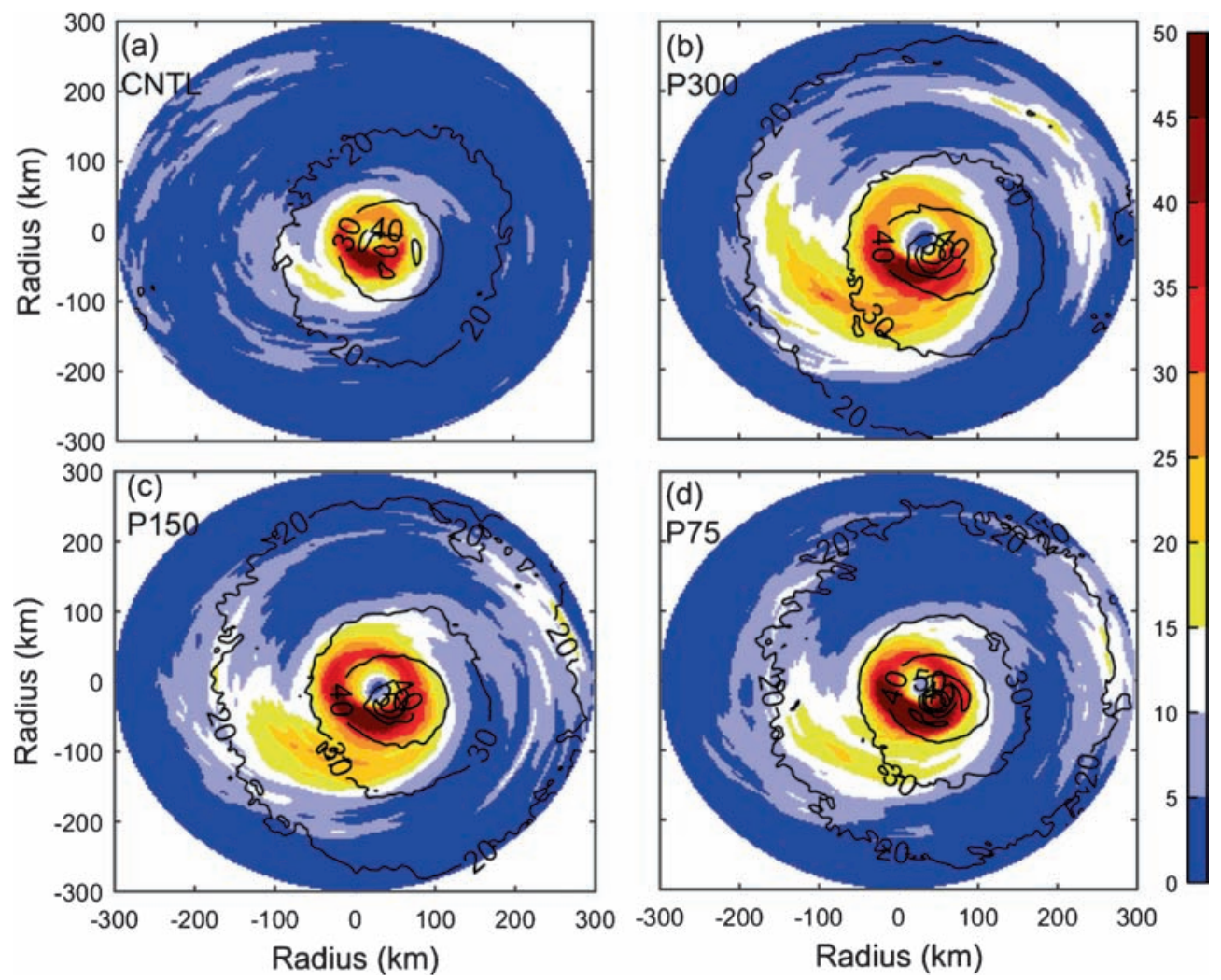

Figure 12. Plane view of the rain rate $\left(\mathrm{mm} \mathrm{h}^{-1}\right)$ for SET2 (a) CNTL, (b) P300, (c) P150, and (d) P75, time-averaged during 39-60 hrs. Black contours represent the wind speed.

P300. It is also found that the tangential wind in P75, near eyewall, is relatively stronger (about $10 \mathrm{~m} \mathrm{~s}^{-1}$ ) than other experiments and is more focused towards the center of storm for SET2 (figure 12). RMW for P300, P150 and P75 are 41, 35 , and $34 \mathrm{~km}$ respectively during SET2. Similar results are found for SET1 with 37, 30, and $24 \mathrm{~km}$ RMW for P300, P150, and P75 respectively (figure not shown). These results are consistent with findings of Wang (2009).

\subsection{Vertical profile}

TC gets energy from the sea surface to develop and to maintain its strength. This energy is very much dependent on the SST. Hence modification of SST, both in terms of magnitude and radial distance, will impact the amount and distribution of the energy supplied from the surface to the system (convection), which affects the vertical structure and distribution of different features, i.e., wind speed (WS), air temperature $(T)$, equivalent potential temperature $\left(\theta_{\mathrm{e}}\right)$, and vertical velocity.

\subsubsection{Wind speed and air temperature}

Figures 13-15 show the radius-pressure time averaged WS and $T$ difference between the sensitivity experiments and CNTL. The time averaging period for SET1, SET2, and SET3 are 18-36, 39-60 and 39-60 hrs, respectively. Here positive values indicate that sensitivity experiments produce stronger WS and $T$ with respect to CNTL. It is found that sensitivity experiments simulate relatively warmer $T$ with respect to CNTL throughout the vertical column except very near to the center of the storm between 600 and $400 \mathrm{hPa}$ for P300 (figure 13a) and 800-500 hPa for P150 (figure 13b). Hence P75 simulate about 1-2 K warmer eye than P300 and P150 for SET1 (figure 13). The upper levels (i.e., 400$150 \mathrm{hPa}$ ) are relatively warmer than CNTL and extended horizontally outside the eyewall for P300 (figure 13a) and P150 (figure 13b) with respect to P75 (figure 13c). Higher temperature in the upper troposphere requires more heat energy in order to rise an air parcel from the boundary layer to an upper layer in a convective updraft. Hence warmer upper troposphere produces a relatively stable condition for P300 and P150 than P75. Since the conditions are relatively more unstable for P75, due to the relatively cooler upper troposphere, it helps in more convective activity and hence the stronger storm. It is also found that WS differences between P75 and CNTL (figure 13c) are about $4 \mathrm{~m} \mathrm{~s}^{-1}$ larger than that for P300 (figure 13a) and P150 (figure 13b), especially near the eyewall region. Hence P75 simulated WS are relatively stronger 
(a) P300

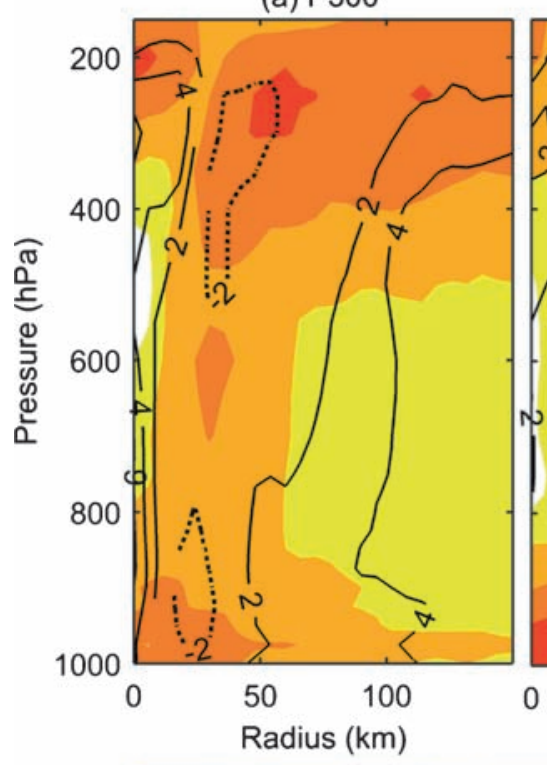

(b) P150

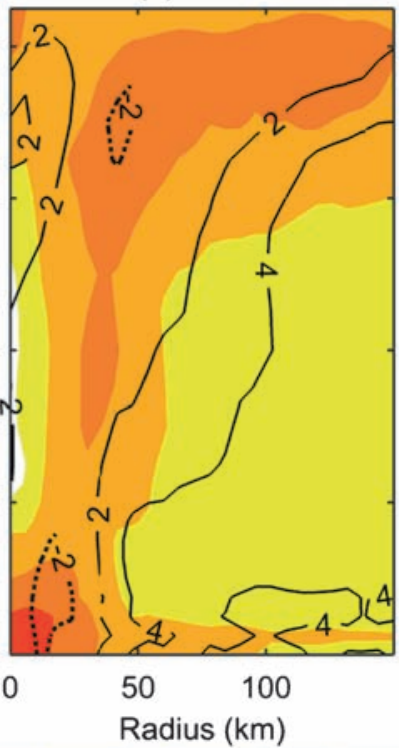

(c) P75

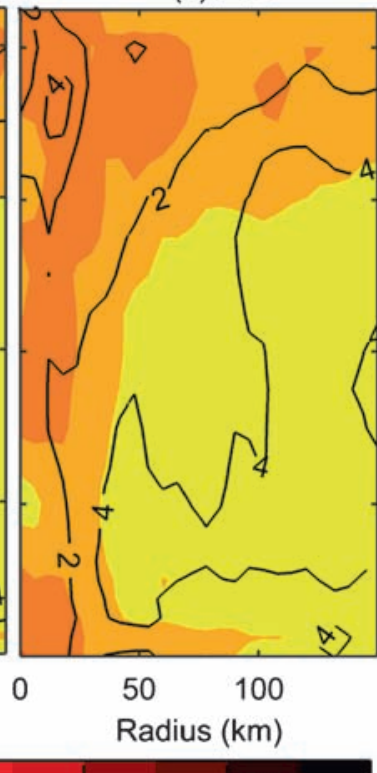

4 5

Figure 13. Radial-pressure cross section of differences between the sensitivity experiments and CNTL of azimuthal mean air temperature, i.e., $T$ (K, shaded) and wind speed, i.e., WS ( $\mathrm{m} \mathrm{s}^{-1}$, contour) for SET1, time-averaged between 18 and 36 hrs. (a) P300 minus CNTL, (b) P150 minus CNTL, and (c) P75 minus CNTL. Dash contours indicate the negative values.

(a) P300

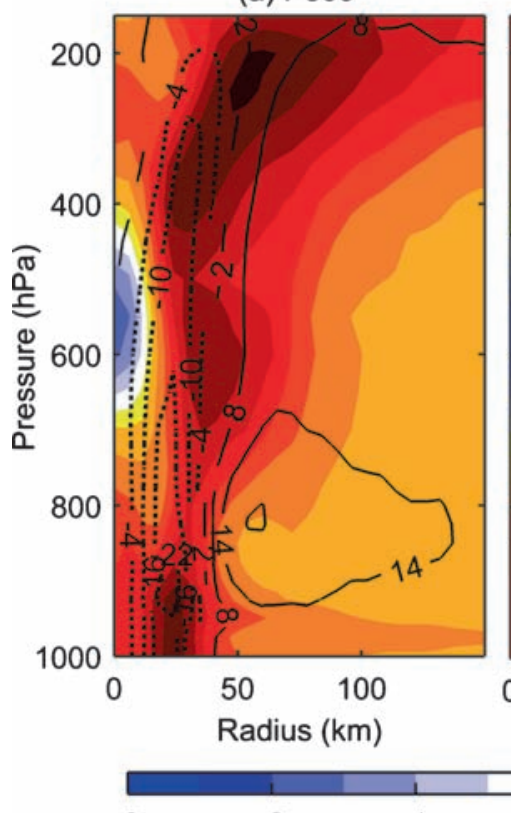

$-3-2$ (b) P150

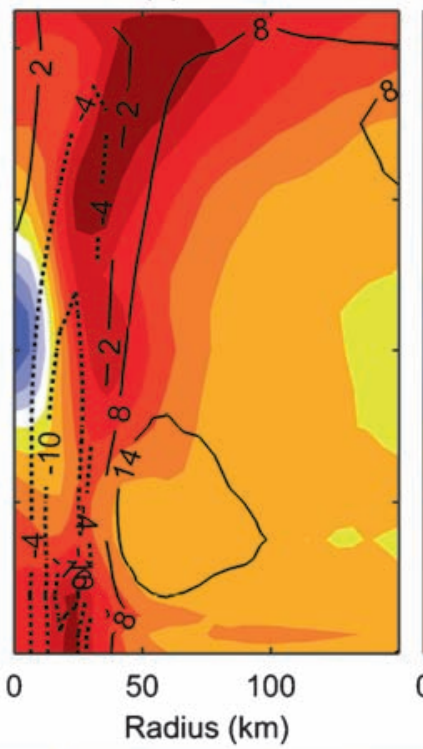

(c) P75

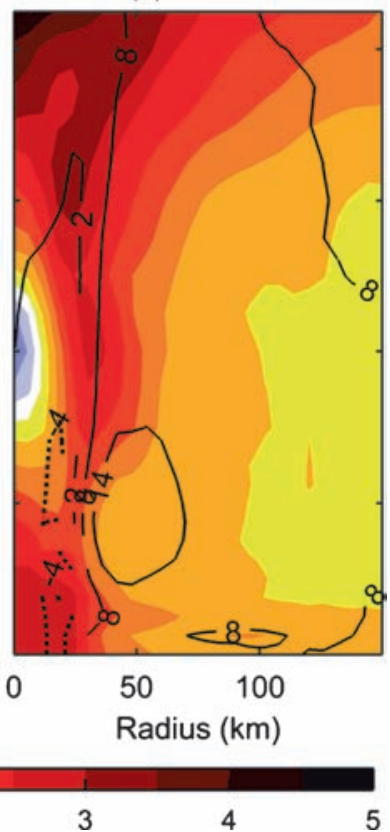

Figure 14. Same as figure 13, but for SET2, time-averaged between 39 and 60 hrs.

than other sensitivity experiments, i.e., P300 and P150, which facilitate its intensification.

Similar trends are found for SET2 (figure 14) but more than $2.5 \mathrm{~K}$ warmer and $10 \mathrm{~m} \mathrm{~s}^{-1}$ stronger $T$ and WS difference respectively between the sensitivity and CNTL experiments near the eyewall than SET1 (figure 13). SET2 (figure 14) shows relatively cooler $(>2 \mathrm{~K})$ middle layers, i.e., 700$400 \mathrm{hPa}$, and weaker WS difference $\left(>5 \mathrm{~m} \mathrm{~s}^{-1}\right)$ within the eye than SET1 (figure 14). The magnitude of WS difference between 900 and $600 \mathrm{hPa}$ reaches up to $14 \mathrm{~m} \mathrm{~s}^{-1}$ (figure 14a) and is more confined towards the eyewall region in P75 than in P300 and P150 (figure 14). Results show that 
(a) N300

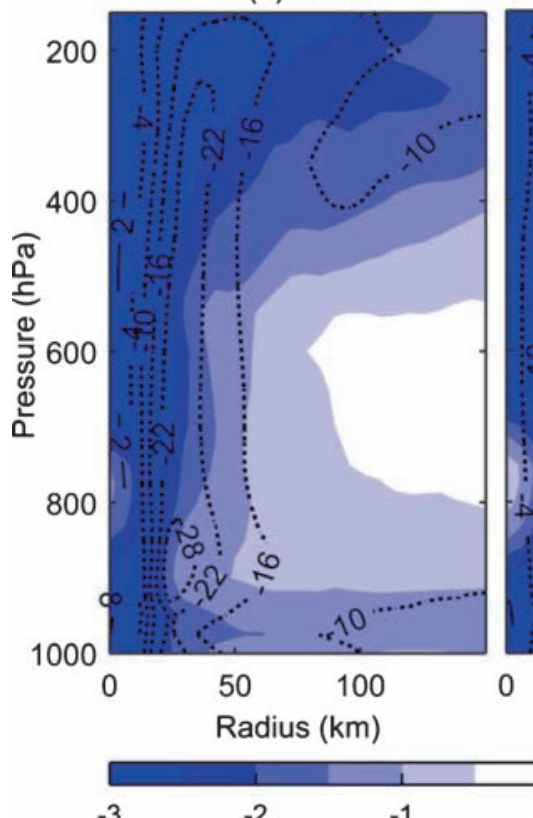

(b) N150

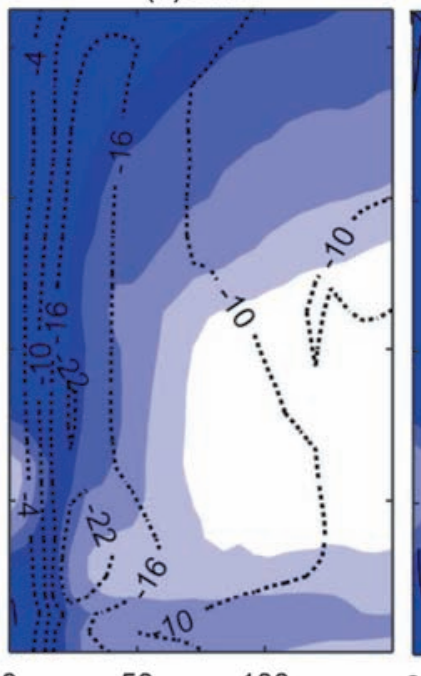

(c) N75

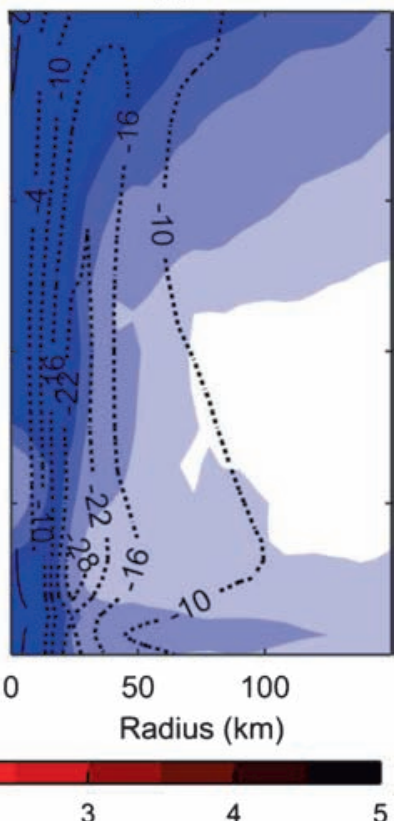

Figure 15. Same as figure 14, but for SET3 (a) N300 minus CNTL, (b) N150 minus CNTL, and (c) N75 minus CNTL.

P75 simulated storm has a relatively stronger wind near the eyewall than P300 (figures 13a, 14a) and P150 (figures 13b, 14b), which helps the system in more convective activities and hence produces a stronger storm.

Unlike positive SST anomaly experiments, negative SST anomaly experiments produce weaker winds $\left(>5 \mathrm{~m} \mathrm{~s}^{-1}\right)$ and cooler $T(>1 \mathrm{~K})$ than CNTL, within $50 \mathrm{~km}$ from the storm center, throughout the intensification period, i.e., 39-60 hrs (figure 15). WS differences near the eyewall is more than $15 \mathrm{~m} \mathrm{~s}^{-1}$ weaker and eye is about $3 \mathrm{~K}$ cooler than CNTL, which suppress the intensification of the storm and hence simulate weaker storm than CNTL. The negative SST anomaly experiments show a minimal impact on the vertical distribution of $T$ of the storm for N150 and N75 (figure 15b-c) but N300 simulated $T$ is relatively cooler throughout the vertical column (figure 15a). N150 simulated WS is about $6 \mathrm{~m} \mathrm{~s}^{-1}$ stronger than N300 and N75 within 1000-800 hPa levels near the eyewall (figure 15).

\subsubsection{Equivalent potential temperature and upward vertical velocity}

Figures 16-17 show the radius-pressure time averaged differences of upward vertical velocity $(w)$ and equivalent potential temperature $\left(\theta_{\mathrm{e}}\right)$ between the sensitivity experiments and CNTL. The time averaging period for SET1, SET2, and SET3 are 18-36 hrs, 39-60 hrs, and 39-60 hrs respectively. Here positive values indicate that sensitivity experiments produce stronger $w$ and $\theta_{\mathrm{e}}$ with respect to CNTL.

It is found that sensitivity experiments simulate relatively larger $\theta_{\mathrm{e}}$, reaching up to $2 \mathrm{~K}$, with respect to CNTL throughout the vertical column for SET1 (figure 16). $\theta_{\mathrm{e}}$ differences are more in the upper $(300-150 \mathrm{hPa})$ and lower $(1000-900 \mathrm{hPa})$ vertical levels by $2 \mathrm{~K}$ and $1 \mathrm{~K}$ respectively. It is found that these differences in $\theta_{\mathrm{e}}$ are more concentrated towards the eye, $0-25 \mathrm{~km}$, for P75 (figure 16c) while $0-150 \mathrm{~km}$ for P300 (figure 16a) and P150 (figure $16 \mathrm{~b}$ ). $\mathrm{P} 75$ produces $1 \mathrm{~K}$ larger $\theta_{\mathrm{e}}$ within the eye, whereas, $0.5 \mathrm{~K}$ lesser $\theta_{\mathrm{e}}$ outward, than P300 and P150. A comparison of $w$ difference within the eye of the storm shows weaker $w$ for P75 (-0.2 to $0 \mathrm{~m} \mathrm{~s}^{-1}$ within $400-150 \mathrm{hPa}$ ) than P300 (0 to $1.2 \mathrm{~m} \mathrm{~s}^{-1}$ within $400-150 \mathrm{hPa}$ ) and P150 (0 to $0.8 \mathrm{~m} \mathrm{~s}^{-1}$ within $400-150 \mathrm{hPa}$ ). All the simulations show a relatively weaker $w$ within different narrow columns (roughly $0-40$ and 50$75 \mathrm{~km}$ ) throughout the vertical columns (figure 16).

A comparison of all the simulations for SET2 shows a relatively larger $\theta_{\mathrm{e}}$ throughout the vertical column except for between 650 and $500 \mathrm{hPa}$ near the eye of the storm (figure 17). The $\theta_{\mathrm{e}}$ differences for upper (300-150 hPa) and lower (1000$850 \mathrm{hPa}$ ) vertical levels are larger, more than $5 \mathrm{~K}$ and $2 \mathrm{~K}$ respectively, for P300, P150 and P75. It is also found that $\theta_{\mathrm{e}}$ differences for P75 are more concentrated towards the eye than other experiments. $w$ differences for all the simulations are positive throughout the vertical column except within 0-50 km and the lower vertical levels (figure 17). 
(a) P300

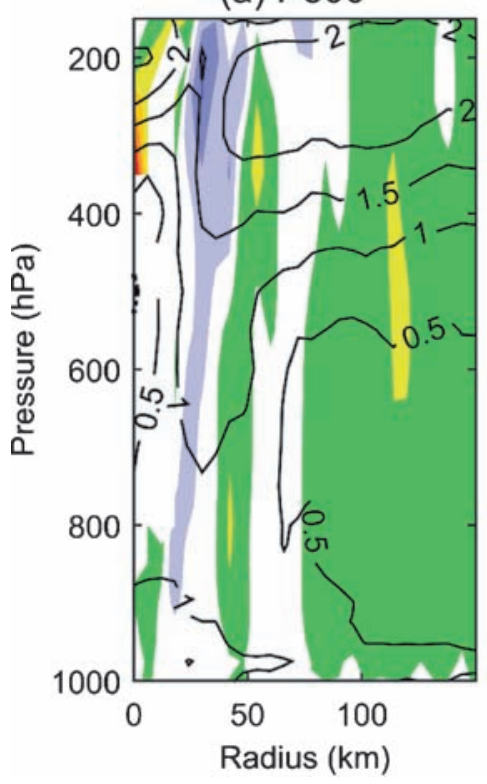

(b) P150

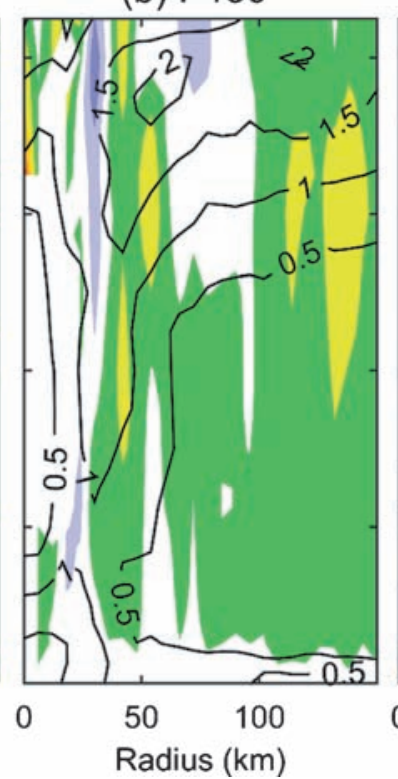

(c) P75

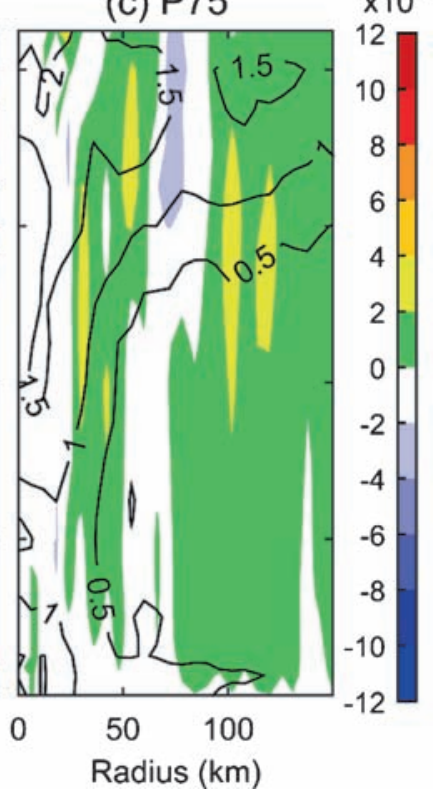

Figure 16. Radial-pressure cross section of differences between the sensitivity experiments and CNTL azimuthally mean equivalent potential temperature i.e., $\theta_{\mathrm{e}}\left(\mathrm{K}\right.$, contour) and upward vertical velocity i.e., $w\left(\mathrm{~m} \mathrm{~s}^{-1}\right.$, shaded) for SET1, timeaveraged between 18 and 36 hrs. (a) P300 minus CNTL, (b) P150 minus CNTL, and (c) P75 minus CNTL. $\theta_{\mathrm{e}}$ positive differences are shown in solid lines and $\theta_{\mathrm{e}}$ negative differences are shown in dotted lines.
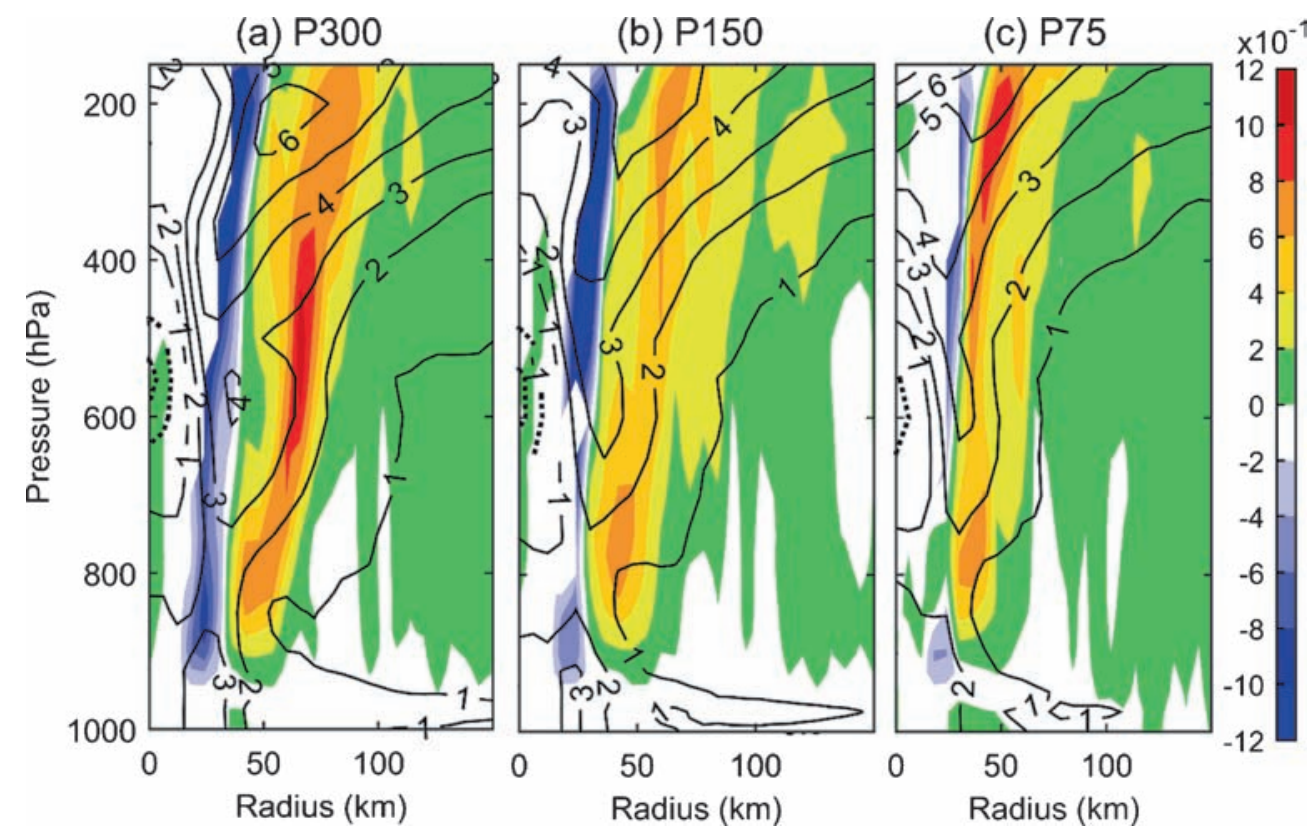

Figure 17. Same as figure 16, but for SET2, time-averaged between 39 and $60 \mathrm{hrs.}$

It is found that P75 simulated $w$ is relatively stronger $\left(>0.2 \mathrm{~m} \mathrm{~s}^{-1}\right.$ than CNTL) near the eyewall and more concentrated within a smaller area (i.e., $40-60 \mathrm{~km}$ from the storm centre) than other experiments.

All the negative sensitivity experiments simulate a lower $\theta_{\mathrm{e}}$, reaching up to $14 \mathrm{~K}$, than $\mathrm{CNTL}$ throughout the vertical column (figure 18). A comparison of all the simulations for SET3 shows that $w$ is weaker than CNTL for all the simulations except N75 very near to the storm center. The $w$ differences within the eye of the N75 are varying between 0 and $0.4 \mathrm{~m} \mathrm{~s}^{-1}$. Hence $w$ differences simulated by negative experiments decrease significantly, reaching up to $-1.2 \mathrm{~m} \mathrm{~s}^{-1}$ with respect to CNTL, within the eyewall of the storm. 


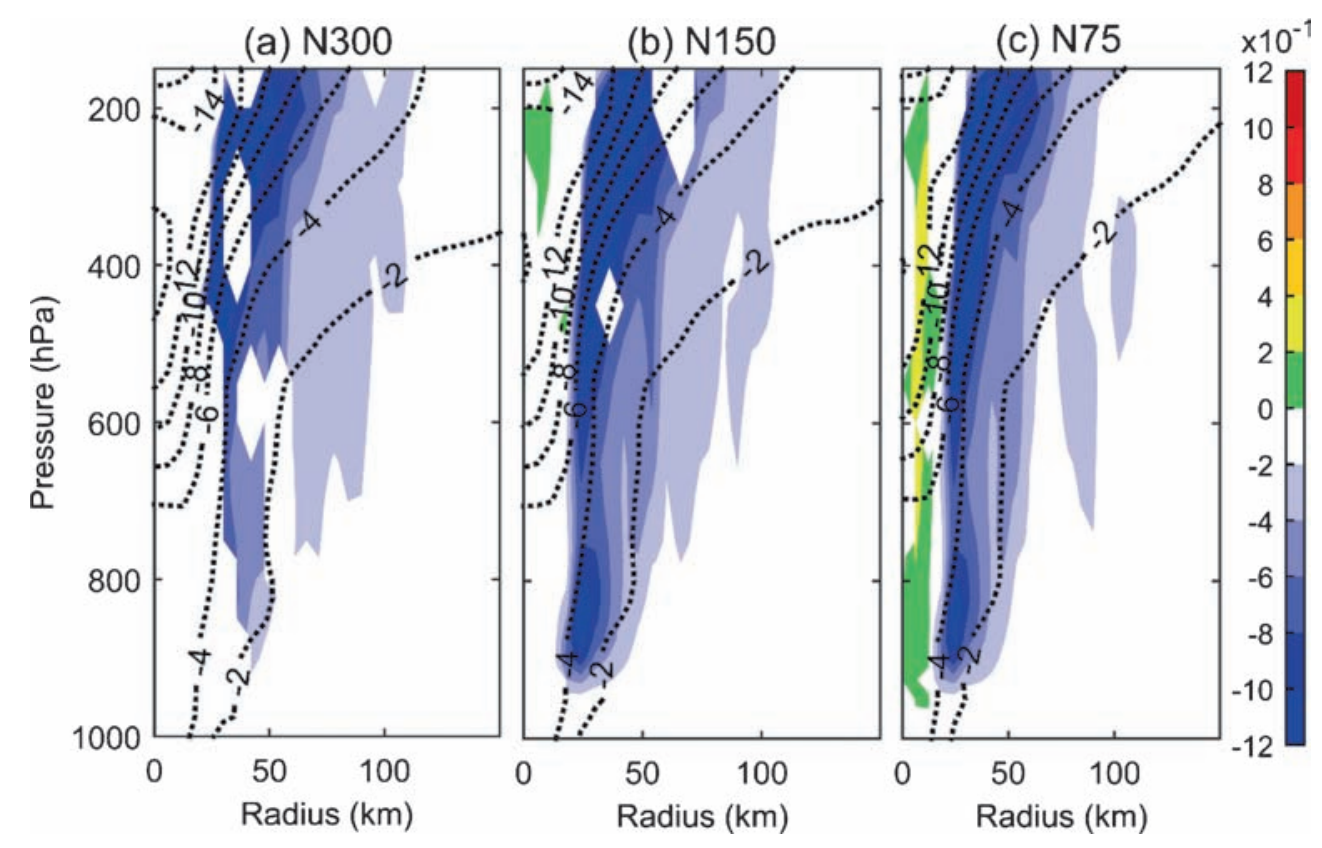

Figure 18. Same as figure 17, but for SET3 (a) N300 minus CNTL, (b) N150 minus CNTL, and (c) N75 minus CNTL time-averaged between 39 and 60 hrs.

The static energy of air parcels $\left(\theta_{\mathrm{e}}\right)$, is an important variable to understand the thermodynamic structure and origin of different air masses. All the simulations, except negative experiments, show stronger $\theta_{\mathrm{e}}$ in the lower and upper levels with relatively lower $\theta_{\mathrm{e}}$ in the middle level (figures 1618) and $\theta_{\mathrm{e}}$ gradients are strongest for P75 during the mature phase (figure 17). Strong $\theta_{\mathrm{e}}$ gradients produce more unstable conditions for deep convection, which favour the upward vertical velocity; hence, facilitates further intensification of the TC (Liu et al. 1997). Lower $\theta_{\mathrm{e}}$ centred in the middle troposphere in the eye is due to extreme dryness, whereas, stronger $\theta_{\mathrm{e}}$ in the upper and lower vertical levels are due to descend from the tropopause and upward transport of surface fluxes respectively (Liu et al. 1997).

\section{Conclusions}

The sensitivity of the inner-core size, track, and intensity of VSCS Phailin (2013) to the radial distribution of SST has been examined using WRFARW model. A series of numerical simulations, i.e., CNTL1, CNTL, and sensitivity experiments (P300, P150, P75, N300, P150, and N75) are conducted. The CNTL1 and CNTL experiments are carried out without and with SST updates respectively, whereas sensitivity experiments are simulated by modifying the SST at different radial extent. Because of the presence of more realistic information of the SST, CNTL simulation produces more than $15 \%$ improved track and intensity (in terms of MSLP and MWS) than CNTL1.

It is found that SST anomaly under the storm core region significantly impact the TC's track, TS, and intensity. It is also found that the modifications in SST, in terms of radial extent, do not change the TS significantly, but positive (negative) SST anomaly under the storm core increases (decreases) the TS of the storm particularly during the mature phase of the storm. Positive (negative) SST anomaly induced rightward (leftward) drifts in track forecast. It is noted that P300 and N300 experiments have the largest drifts in northwestward and south-eastward directions respectively. Although, all the simulations were started from the same initial intensity, positive (negative) SST anomaly experiments simulated more than $15 \mathrm{hPa}$ stronger (weaker) storm with respect to IMD at the end of the simulation, i.e., $72 \mathrm{hrs,} \mathrm{with}$ an early (delayed) intensification of the storm after $18 \mathrm{hrs}$ (36 hrs) of the simulation. It was noticed that P75 (N150), for which radius of constant SST anomalies were about 2-2.5 times of RMW, simulated the strongest storm respectively among all the positive (negative) simulations.

Among all the positive (negative) SST anomaly experiments, P75 (N150) simulated $\mathrm{WS}_{10}$, SEF, rain rate, $\mathrm{WS}$, and $w$ were strongest and were concentrated in the vicinity of the eyewall. Stronger winds in the outer region lead to stronger SEF in the outer region, which favours more convective activity in the outer rainbands and reduces the storm intensity. It was found that the development 
phase of storms has a stronger temporal gradient in $\mathrm{WS}_{10}$ and $\mathrm{SEF}$ than matured phase.

The $T$ and $\theta_{\mathrm{e}}$ simulated in P75 storm has stronger magnitudes both at the lower and upper levels and relatively cooler in the middle level near the eye during the mature phase of storm. It was found that $T$ of P75 storm were relatively cooler in the upper vertical levels (i.e., 400-150 hPa) beyond the eyewall. Cooler upper level produces an unstable atmosphere which facilitates more convection and hence the stronger storm. The P75 storm has the strongest $\theta_{\mathrm{e}}$ gradient, which favours the deep convection and facilitates the storm intensification. Sensitivity experiments simulated a stronger $\mathrm{WS}_{10}$, $\mathrm{SEF}$, rain rate, WS, $w, T$, and $\theta_{\mathrm{e}}$ during maturing phase than the developing phase within the eyewall region.

These results suggest that SST below the innercore and outside the eyewall up to a radius of about 2-2.5 times of RMW have substantial impact on storm core and strongly affects the TC characteristics particularly during the rapid intensification and mature period of the storm. The results are consistent with the finding of Wang and Xu (2010) and $\mathrm{Xu}$ and Wang (2010a).

\section{Acknowledgements}

The authors thank the Indian Institute of Technology, Bhubaneswar, India for providing necessary infrastructural facilities for research and fellowship. They are grateful to the India Meteorological Department (IMD), National Centres for Environmental Prediction (NCEP) - National Oceanic and Atmospheric Administration (NOAA) for providing best track cyclone data, initial and boundary conditions, SST data and express their gratitude to the National Centre for Atmospheric Research (NCAR) for using their WRF-ARW model for carrying out this study.

\section{References}

Bender M A and Ginis I 2000 Real-case simulations of hurricane-ocean interaction using a high-resolution coupled model: Effects on hurricane intensity; Mon. Weather Rev. 128(4) 917-946.

Black P G and Holland G J 1995 The boundary layer of tropical cyclone Kerry (1979); Mon. Weather Rev. 123(7) 2007-2028.

Bosart L F, Velden C S, Bracken W E, Molinari J and Black P G 2000 Environmental influences on the rapid intensification of hurricane Opal (1995) over the Gulf of Mexico; Mon. Weather Rev. 128(2) 322.

Chen H, Zhang D-L, Carton J and Atlas R 2011 On the rapid intensification of hurricane Wilma (2005). Part I: Model prediction and structural changes; Wea. Forecasting 26(6) 885-901.
Cione J J and Uhlhorn E W 2003 Sea surface temperature variability in hurricanes: Implications with respect to intensity change; Mon. Weather Rev. 131(8) 1783-1796.

Davis C and Bosart L F 2002 Numerical simulations of the genesis of hurricane Diana (1984). Part II: Sensitivity of track and intensity prediction; Mon. Weather Rev. 130(5) 1100-1124.

Demaria M and Kaplan J 1994 Sea surface temperature and the maximum intensity of Atlantic tropical cyclones; J. Climate 7(9) 1324-1334.

Dudhia J 1989 Numerical study of convection observed during the winter monsoon experiment using a mesoscale two-dimensional model; J. Atmos. Sci. 46(20) 30773107.

Ek M B, Mitchell K E, Lin Y, Rogers E, Grunmann P, Koren V, Gayno G and Tarpley J D 2003 Implementation of Noah Land Surface Model advances in the National Centers for Environmental Prediction operational mesoscale Eta model; J. Geophys. Res. 1088851.

Emanuel K 2005 Increasing Destructiveness of tropical cyclones over the past 30 years; Nature 436 686-688.

Emanuel K A 1986 An air-sea interaction theory for tropical cyclones. Part I: Steady-state maintenance; J. Atmos. Sci. 43(6) 585-605.

Emanuel K A 1987 The dependence of hurricane intensity on climate; Nature 326(6112) 483-485.

Emanuel K A 1988 The maximum intensity of hurricanes; J. Atmos. Sci. 45(7) 1143-1155.

Gemmill W, Katz B and Li X 2007 Daily real-time, global sea surface temperature - high-resolution analysis: RTG_SST_HR; Environmental Modelling Center, National Centres for Environmental Prediction, National Weather Service, NOAA; Camp Spring, MD, 20746.

Holliday C R and Thompson A H 1979 Climatological characteristics of rapidly intensifying typhoons; Mon. Weather Rev. 107(8) 1022-1034.

Holton J R 2004 An Introduction to dynamic meteorology; 4 edn, Elsvier Academic Press.

Hong S-Y and Lim J-O J 2006 The WRF single-moment 6-class microphysics scheme; J. Korean Meteor. Soc. 42 129-151.

Hong S-Y, Noh Y and Dudhia J 2006 A new vertical diffusion package with an explicit treatment of entrainment processes; Mon. Weather Rev. 134 2318-2341.

Hong S-Y, Park H, Cheong H-B, Kim J-E E, Koo M-S, Jang J, Ham S, Hwang S-O, Park B-K, Chang E-C and Li H 2013 The Global/Regional Integrated Model system (GRIMs); Asia-Pacific J. Atmos. Sci. 49(2) 219-243.

Houze R A, Cetrone J, Brodzik S R, Chen S S, Zhao W, Lee W-C, Moore J A, Stossmeister G J, Bell M M and Rogers R F 2006 The hurricane rainband and intensity change experiment: Observations and modeling of hurricanes Katrina, Ophelia, and Rita; Bull. Am. Meteorol. Soc. 87(11) 1503-1521.

IMD 2013 Very severe cyclonic storm, PHAILIN over the Bay of Bengal (08-14 October 2014): A report; Cyclone Warning Division; India Meteorological Department, New Delhi.

Kain J S 2004 The Kain-Fritsch convective parameterization: An update; J. Appl. Meteor. 43 170-181.

Kaplan J and DeMaria M 2003 Large-scale characteristics of rapidly intensifying tropical cyclones in the North Atlantic basin; Wea. Forecasting 18(6) 1093-1108.

Karyampudi V M, Lai G S and Manobianco J 1998 Impact of initial conditions, rainfall assimilation, and cumulus parameterization on simulations of hurricane Florence (1988); Mon. Weather Rev. 126(12) 3077-3101.

Krishnamurti T N, Pattnaik S, Stefanova L, Kumar T S V V, Mackey B P, O'Shay A J and Pasch R J 2005 The 
hurricane intensity issue; Mon. Weather Rev. 133(7) 1886-1912.

Liu Y, Zhang Da-Lin and Yau M K 1997 A multiscale numerical study of hurricane Andrew (1992). Part I: Explicit simulation and varification; Mon. Weather Rev. 125(12) 3073-3093.

Malkus J S and Riehl H 1960 On the dynamics and energy transformations in steady-state hurricanes; Tellus A 12(1) 1-20.

Mandal M, Mohanty U C, Sinha P and Ali M M 2007 Impact of sea surface temperature in modulating movement and intensity of tropical cyclones; Nat. Hazards 41(3) 413-427.

Marks F D, Shay L K and PDT-5 1998 Landfalling tropical cyclones: Forecast problems and associated research opportunitis; Bull. Am. Meteorol. Soc. 79(2) 305-323.

Miller B I 1958 On the maximum intensity of hurricanes; J. Meteorol. 15(2) 184-195.

Miyamoto Y and Takemi T 2010 An effective radius of the sea surface enthalpy flux for the maintenance of a tropical cyclone; Atmos. Sci. Lett. 11(4) 278-282.

Mlawer E J, Taubman S J, Brown P D, Iacono M J and Clough S A 1997 Radiative transfer for inhomogeneous atmospheres: RRTM, a validated correlated-k model for the longwave; J. Geophys. Res. 102 16,663-16,682.

Ooyama K 1969 Numerical simulation of the life cycle of tropical cyclones; J. Atmos. Sci. 26(1) 3-40.

Palmen E 1948 On the formation and structure of tropical hurricanes; Geophysica 3 26-38.

Pattnaik S and Krishnamurti T N 2007 Impact of microphysical processes on hurricane intensity, Part II: Sensitivity experiments; Meteorol. Atmos. Phys. 97 127-147.

Pattnaik S, Inglish C and Krishnamurti T N 2010 Influence of rain rate initialization, cloud microphysics and cloud torques on Hurricane Intensity; Mon. Wea. Rev. 139 627-649.

Rappaport E N, Franklin J L, Avila L A, Baig S R, Beven J L, Blake E S, Burr C A, Jiing J-G, Juckins C A, Knabb R D, Landsea C W, Mainelli M, Mayfield M, McAdie C J, Pasch R J, Sisko C, Stewart S R and Tribble A N 2009 Advances and challenges at the National Hurricane Center; Wea. Forecasting 24(2) 395-419.

Rogers R, Aberson S, Black M, Black P, Cione J, Dodge P, Gamache J, Kaplan J, Powell M, Dunion J, Uhlhorn E, Shay N and Surgi N 2006 The intensity forecasting experiment: A NOAA multiyear field program for improving tropical cyclone intensity forecasts; Bull. Am. Meteorol. Soc. 87(11) 1523-1537.
Rotunno R and Emanuel K A 1987 An air-sea interaction theory for tropical cyclones. Part II: Evolutionary study using a nonhydrostatic axisymmetric numerical model; J. Atmos. Sci. 44(3) 542-561.

Shapiro L J and Goldenberg S B 1998 Atlantic sea surface temperatures and tropical cyclone formation; J. Climate 11(4) 578-590.

Shay L K, Goni G J and Black P G 2000 Effects of a warm oceanic feature on hurricane Opal; Mon. Weather Rev. 128(5) 1366-1383.

Skamarock W C, Klemp J B, Dudhia J, Gill D O, Barker D M, Duda M G, Huang X-Y, Wang W and Powers J G 2008 A description of the advanced research WRF Version 3. Tech. Rep. NCAR/TN-475+STR, National Centre for Atmospheric Research, Boulder, Colorado.

Sun Y, Zhong Z, Ha Y, Wang Y and Wang X 2013 The dynamic and thermodynamic effects of relative and absolute sea surface temperature on tropical cyclone intensity; Acta Meteorol. Sin. 27(1) 40-49.

Trenberth K E and Shea D J 2006 Atlantic hurricanes and natural variability in 2005; Geophys. Res. Lett. 33(12) $1-4$.

Tuleya R E and Kurihara Y 1982 A note on the sea surface temperature sensitivity of a numerical model of tropical storm genesis; Mon. Weather Rev. 110(12) 2063-2069.

Wang Y 2009 How do outer spiral rainbands affect the tropical cyclone structure and intensity? J. Atmos. Sci. 66(5) 1250-1273.

Wang Y and Wu C-C 2004 Current understanding of tropical cyclone structure and intensity changes - A review; Meteorol. Atmos. Phys. 87 257-278.

Wang Y and $\mathrm{Xu}$ J 2010 Energy production, frictional dissipation, and maximum intensity of a numerically simulated tropical cyclone; J. Atmos. Sci. 67(1) 97-116.

$\mathrm{Xu}$ J and Wang Y 2010a Sensitivity of tropical cyclone innercore size and intensity to the radial distribution of surface entropy flux; J. Atmos. Sci. 67(6) 1831-1852.

$\mathrm{Xu}$ J and Wang Y 2010b Sensitivity of the simulated tropical cyclone inner-core size to the initial vortex size; Mon. Weather Rev. 138(11) 4135-4157.

Yun K, Chan J C L and Ha K 2012 Effects of SST magnitude and gradient on typhoon tracks around east Asia: A case study for typhoon Maemi (2003); Atmos. Res. 109-110 $36-51$.

Zhang D and Anthes R A 1982 A high-resolution model of the planetory boundary layer-sensitivity tests and comparisons with SESAME-79 Data; J. Appl. Meteor. 21 $1594-1609$. 